\title{
A small cichlid species flock from the Upper Miocene (9-10 MYA) of Central Kenya
}

\author{
Melanie Altner • Bettina Reichenbacher
}

Received: 22 March 2020/Revised: 16 June 2020/ Accepted: 13 July 2020/Published online: 18 August 2020

(C) The Author(s) 2020

\begin{abstract}
Fossil cichlids from East Africa offer unique insights into the evolutionary history and ancient diversity of the family on the African continent. Here we present three fossil species of the extinct haplotilapiine cichlid $\dagger$ Baringochromis gen. nov. from the upper Miocene of the palaeolake Waril in Central Kenya, based on the analysis of a total of 78 articulated skeletons. $†$ Baringochromis senutae sp. nov., $\dagger B$. sonyii sp. nov. and $\dagger B$. tallamae sp. nov. are superficially similar, but differ from each other in oral-tooth dentition and morphometric characters related to the head, dorsal fin base and body depth. These findings
\end{abstract}

Guest editors: S. Koblmüller, R. C. Albertson, M. J. Genner, K. M. Sefc \& T. Takahashi / Advances in Cichlid Research IV: Behavior, Ecology and Evolutionary Biology.

Electronic supplementary material The online version of this article (https://doi.org/10.1007/s10750-020-04358-z) contains supplementary material, which is available to authorized users.

M. Altner $(\bowtie) \cdot$ B. Reichenbacher

Department of Earth and Environmental Sciences,

Palaeontology \& Geobiology, Ludwig-Maximilians-

Universität München (LMU), Richard-Wagner-Strasse 10,

80333 Munich, Germany

e-mail: m.altner@1rz.uni-muenchen.de

B. Reichenbacher

e-mail: b.reichenbacher@1rz.uni-muenchen.de

B. Reichenbacher

GeoBio-Center at LMU, Richard-Wagner-Strasse 10, 80333 Munich, Germany indicate that they represent an ancient small species flock. Possible modern analogues of palaeolake Waril and its species flock are discussed. The three species of $\dagger$ Baringochromis may have begun to subdivide their initial habitat by trophic differentiation. Possible sources of food could have been plant remains and insects, as their fossilized remains are known from the same place where $\dagger$ Baringochromis was found.

Keywords Cichlid fossils - Pseudocrenilabrinae · Palaeolake $\cdot$ Small species flock $\cdot$ Late Miocene

\section{Introduction}

The tropical freshwater fish family Cichlidae and its estimated 2285 species is famous for its high degree of phenotypic diversity, trophic adaptations and specialized behaviors, and represents an established model in studies dealing with evolutionary processes (Seehausen, 2006, 2015; Brawand et al., 2014; Salzburger, 2018). The monophyly of the family is well supported by morphological and molecular data (Stiassny, 1981a; Kullander, 1998; Sparks \& Smith, 2004; Betancur et al., 2017), but most morphological synapomorphies relate to soft tissue or delicate bone structures, which are rarely preserved in fossils (Casciotta \& Arratia, 1993). The only cichlid apomorphy with a relatively high potential to be well preserved in the fossil record is related to their saccular otoliths ('ear stones'), which 
display a specific ornament termed the 'anterocaudal pseudocolliculum' on their mesial surface (Gaemers, 1984). Fortunately, modern cichlid fishes also possess several morphological traits that typify them. These include: a bipartite lateral line, a specific composition of the caudal skeleton and fin (i.e. eight principal caudal fin rays in each lobe, two epural bones, uroneural and parhypural each autogenous, preural centrum 2 with autogenous haemal spine and reduced neural spine, preural centrum 3 with fused haemal spine), a single dorsal fin consisting of spines and rays, a pelvic fin with one spine and five rays, and a hyoid bar with five branchiostegals (Vandewalle, 1973; Barel et al., 1976; Cichocki, 1976; Fujita, 1990; Sebilia \& Andreata, 1991; Carpenter \& Niem, 2001; Takahashi \& Nakaya, 2002). It is essentially this combination of characters that enables one to identify a fossil fish as a cichlid.

The subdivision of the Cichlidae into four subfamilies-Etroplinae, Ptychochrominae, Cichlinae (Neotropical cichlids) and Pseudocrenilabrinae (African cichlids) - is well established based on molecular data (Sparks \& Smith, 2004). The Pseudocrenilabrinae are famous for their radiations in the Great Lakes of East Africa (Lake Tanganyika, Lake Victoria, Lake Malawi) and they are thought to comprise more than 1,200 species in all (Seehausen, 2006; Koblmüller et al., 2010; Sturmbauer et al., 2011; Salzburger, 2018). As for the family, the synapomorphies that define the subfamilies have a limited fossilization potential (Cichocki, 1976; Stiassny, 1991; Kullander, 1998; Kevrekidis et al., 2019; Penk et al., 2019). The character 'single supraneural', which appears to be a synapomorphy for the Pseudocrenilabrinae in the morphological data matrix of Stiassny (1991), and which is readily recognizable in fossils, actually occurs in the subfamily Cichlinae as well (see Kullander, 1998). Nevertheless, previous studies of fossil cichlids have considerably extended our knowledge of their ancient diversity and biogeography (Malabarba et al., 2014; Murray et al., 2017; Altner et al., 2017; Kevrekidis et al., 2019 (amongst others)). To date, 22 fossil cichlid species are known from Eocene to Pliocene sediments of Africa, Arabia and Europe, but only a few could be classified as members of extant tribes (van Couvering, 1982; Carnevale et al., 2003; Penk et al., 2019; Altner et al., 2020). This subset testifies to the presence of the tribe Oreochromini since at least the middle Miocene (Penk et al., 2019), and implies at least a late Miocene age, and perhaps even a date in the early Miocene, for the origin of the tribe Haplochromini (Altner et al., 2020).

The Haplochromini constitute the most speciose of the 27 recognized tribes of the African cichlids, and are represented by approximately 800 and 600 species in Lakes Malawi and Victoria, respectively (Salzburger et al., 2014). Today they can be found in most areas of Africa, with the exception of the north-western part of the continent (Koblmüller et al., 2008; Schwarzer et al., 2012). The success of the Haplochromini appears to be related to their ability to occupy each of the major trophic niches available in their habitats, including planktivory, abrasion of algae from rocks, scale eating, snail crushing, insect eating, paedophagy, and piscivory (Sturmbauer et al., 2011; Brawand et al., 2014). To cope with their preferred diet, haplochromine species have repeatedly developed specific types of oral and/or pharyngeal dentition or jaws (Albertson et al., 2003; Vranken et al., 2019). A further reason for the success of haplochromine cichlids lies in their specialized modes of reproduction, such as polygynous and/or polygynandrous mating systems and maternal mouthbrooding (Fryer and Iles, 1972; Salzburger et al., 2005).

The present study continues our previous works on the fossil cichlid specimens from the locality Waril (Altner et al., 2017, 2020). We introduce a new extinct cichlid genus and possible member of the Haplochromini, $\uparrow$ Baringochromis gen. nov., represented by three species. Their co-occurrence indicates that an ancient small species flock had evolved in the palaeolake Waril during the late Miocene (9-10 MYA).

\section{Study site}

The study site Waril ( $\left.0^{\circ} 40^{\prime} 56.21^{\prime \prime} \mathrm{N} 35^{\circ} 43^{\prime} 7.43^{\prime \prime} \mathrm{E}\right)$ is located in the Kerio Valley, to the west of the Tugen Hills in the Central Kenya Rift Valley (or Gregory Rift) within the eastern branch of the East African Rift System (Fig. 1a). The Tugen Hills are well known for their Miocene and Pliocene rocks of volcanic, fluvial and lacustrine origin (Bishop \& Chapman, 1970; Bishop and Pickford, 1975; Pickford et al., 2009). The fossiliferous sediments exposed at Waril represent the upper part of the Ngorora Formation (Member E) and date to the upper Miocene (9-10 MYA) (Pickford et al., 2009; Bonnefille, 2010; Rasmussen et al., 2017). According to geological mapping, the palaeolake 

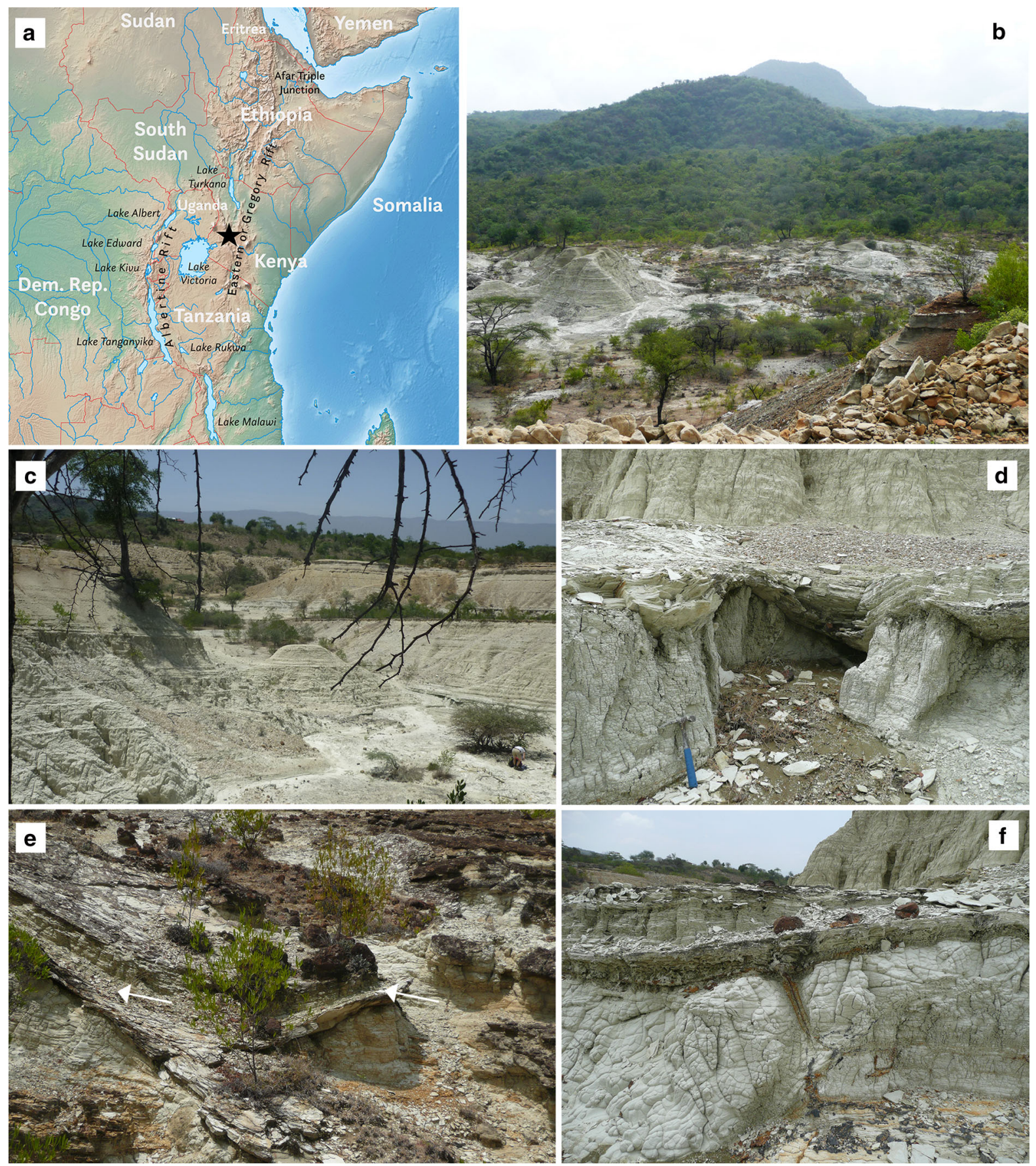

Fig. 1 a Geographic overview of East Africa, showing the position of Waril (indicated with star) in the Gregory Rift in the eastern branch of the East African Rift System. Source: Wikipedia; b, c overview of the outcrop, in the background are the Tugen Hills (b) and the Elgeyo Escarpment (c); d basal lake sediments above volcanic tuff, showing unconformity and palaeorelief; e erosional relicts of tilted and disturbed lake sediments (indicated with arrows) above volcanic tuff at the southern margin of the outcrop; $\mathbf{f}$ detail of basal lake sediments above volcanic tuff, showing crack filled with volcanic debris within the tuff 
Waril may have covered an area of about $30-35 \mathrm{~km}^{2}$ (Pickford, 1978: fig. 4C), but could have been even considerably larger (unpublished information of $\mathrm{M}$. Pickford).

The outcrop Waril is a former quarry exposing finely laminated, up to $10 \mathrm{~m}$ thick lake sediments (Fig. 1b, c) above homogeneous greyish and yellowish volcanic tuffs (Fig. 1d, f; see also Rasmussen et al., 2017: fig. 8). In places, cracks appear within the tuff, which are filled with fine-grained debris derived from basaltic rocks (Fig. 1f). The lake sediments overly the volcanic tuff with a clear unconformity (Fig. 1d,f) and can also fill a palaeo-relief formed by the tuff (Fig. 1d). At the southern periphery of the outcrop, the lake sediments are tilted (rather than horizontally layered), and their bedding is disturbed (Fig. 1e). This may indicate deposition of sediment on the slope of the ancient shoreline, and episodes of subaquatic slumping. Fossil fishes can be found mainly in the basalmost sediments in the centre of the outcrop, c. $2 \mathrm{~m}$ above the tuff (Rasmussen et al., 2017). Their good preservation documents that the ancient lake had anoxic conditions at the bottom. Two fossil cichlid taxa have been described previously: one is an extinct member of the Lake Tanganyika cichlid radiation ( $\dagger$ Tugenchromis pickfordi), and the other is an ancient predatory species of the Haplochromini (†Warilochromis unicuspidatus) (see Altner et al., 2017, 2020). In addition, fossils of well-preserved insects and plant remains have been found (Pickford, 1978; Pickford et al., 2009).

\section{Materials and methods}

\section{Materials}

The entire fossil material from the study site consists of 298 articulated remains of fish skeletons, mostly preserved in lateral view, of which 36 are complete and further six almost complete. The subject of this study are a total of 78 fish fossils ( 24 complete ones, 54 fragments). All fossil specimens were collected during field work in 2013 and 2014 at the site Waril (see study site). They are currently housed at the Department of Earth and Environmental Sciences, Ludwig-Maximilians-Universität München, and will be deposited in Kipsaraman, Baringo County, Kenya, as soon as the new Baringo County Geopark has been established.
The comparative skeletal material of recent species corresponds to that used in Penk et al. (2019, pp. 18-19) and Altner et al. (2020).

\section{Methods}

Methods concerning preparation of fossils, morphometric measurements, imaging and phylogenetic analysis follow Altner et al. (2020). Measurements of the fossil specimens were normalized with reference to body length (BL) as most specimens lack a completely preserved head (BL is the distance from the posterior margin of the opercle to the posterior margin of the hypural plate). The normalized measurements served as input for statistical analyses in PAST 4.02 (Hammer et al., 2001). Normal distribution was tested based on the Shapiro-Wilk test $(P>0.05$ if normal distribution is satisfied). Several morphometric variables revealed covariance with fish size (Pearson, Spearman, $P<0.05$ ); therefore one-way analysis of covariance (ANCOVA, $P<0.05$ ), with SL (in $\%$ of BL) as covariable was applied to evaluate any morphometric differences between the species.

For the phylogenetic analysis the characters of the new fossil taxon were added to the original data matrix of Stiassny (1991) by inserting character states for eight (of 28) characters (respective state indicated in brackets, character specification of fossil in square brackets): Character number 8(0) [simple suture between the vomerine wing and the parasphenoid], 10(0) [no rostrally directed spine on urohyal], 11(0) [number of vertebrae not increased], 13(0) [vomer not notched], 17(1) [six lateral-line tubules on the preopercle], 25(1) [single supraneural], 26(1) [opercular spot developed], 27(1) [lacrimal is single element and followed by tubular second infraorbital]. The morphological matrix was edited in Mesquite 3.61 (Maddison \& Maddison, 1997-2019). Phylogenetic reconstruction was executed under maximum parsimony in TNT 1.1 (Goloboff et al., 2008), using a combination of 'new technology' search options, i.e., parsimony ratchet, tree-drifting and tree-fusing. We used implied weighting $(K=12.0)$ according to Goloboff et al. (2018). In all other cases, the settings were left at their defaults. Clade support was assessed using standard bootstrapping (1000 replicates, absolute frequency values). Clades with bootstrap values $\geq$ $70 \%$ were considered well supported following Hillis 
\& Bull (1993). Phylogenetic trees were visualized and edited in FigTree 1.4.4 (Rambaut, 2018).

\section{Abbreviations}

Abbreviations for measurements

AL, length of anal fin base; Asc, length of premaxillary ascending process; $\mathrm{BH}$, maximum body height; $\mathrm{BH} 2$, body height at anal fin origin; BL, body length; CL, length of caudal fin; DL, length of dorsal fin base; $\mathrm{HH}$, head depth; HL, head length; LJ, length of lower jaw (dentary); Minb, minimum body height; Orbit, horizontal eye diameter; Ped, length of caudal peduncle; SL, standard length; TL, total length; UJ, length of upper jaw (premaxilla); VH, length of pelvic fin base; VL, length of pelvic fin; Vsp, length of pelvic fin spine.

Anatomical abbreviations

ach \& ach', anterior ceratohyal; ang \& ang', anguloarticular; br1-5, branchiostegal rays 1-5; cl, cleithrum; co, coracoid; dent, dentary; dhh, dorsal hypohyal; e \& e', ectopterygoid; eo, epiotic; ep1, ep2, epurals; f \& f', frontal; HS2-3, haemal spines of preural vertebra 2 and 3 ; hyo, hyomandibula; hyp1-5, hypural plates; io1, infraorbital 1 = lacrimal; io2-6, infraorbitals 2-6; iop, interoperculum; mx, maxilla; na, nasal; nlc \& nlc', neurocranial lateral line canal; NS3, neural spine of preural vertebra 3; op, opercle; pa \& pa', parietal; pal \& pal', palatine; pch, posterior ceratohyal; ph, parhypural; pmx, premaxilla; pop \& pop', preopercle; ps, parasphenoid; ptt, posttemporal; PU2-3, preural vertebrae 2-3; q, quadrate; rad, proximal pectoral fin radials; ret $\&$ ret', retroarticular; sca, scapula; scl, supracleithrum; soc, supraoccipital process; sop, suboperculum; st, supratemporal; sy, symplectic; uh, urohyal; un1, uroneural 1; us, terminal centrum (urostyle); vo, vomer; vhh \& vhh', ventral hypohyal; VtPtLDs, ordinal number (s) of vertebrae associated with the pterygiophore of the last dorsal fin spine.

\section{Results}

The studied material revealed that the fossils share a unique skeletal architecture, have essentially similar meristic counts and, with a few exceptions, similar morphometric characters (Table 1). Their osteological and fin-related characters allowed us to attribute them to the family Cichlidae (see Introduction and descriptions below). This was further confirmed by the discovery of one specimen with well-preserved otoliths in situ, which exhibit the apomorphic 'anterocaudal pseudocolliculum' sensu Gaemers (1984).

Phylogenetic analysis using the character matrix constructed by Stiassny (1991) results in a single most parsimonious tree, which places the fossil in the subfamily Pseudocrenilabrinae (Fig. 2). The tree topology is largely consistent with the original topology of Stiassny (1991), slight differences appear to be associated with the use of implied weighting (see Altner et al., 2020 for a detailed discussion).

Moreover, the combination of characters exhibited by the fossil specimens is not known from any extant or extinct cichlid genus. Therefore a new genus, $†$ Baringochromis Altner and Reichenbacher, gen. nov., is introduced (see Systematic palaeontology for details). Among the material attributable to the new genus, 78 specimens were complete enough to be assigned at the level of species. These document the presence of three new species, $\dagger B$. senutae sp. nov., $\dagger B$. sonyii sp. nov., and $\dagger B$. tallamae sp. nov., which are described below. The features that distinguish them from one another relate to the oral dentition and relative proportions of head length, dorsal fin base and body height at point of onset of the anal fin (see Differential diagnosis of species).

\section{Systematic palaeontology}

Cichlidae Bonaparte, 1835

Pseudocrenilabrinae Fowler, 1934

$\dagger$ Baringochromis Altner and Reichenbacher, gen. nov.

Generic Diagnosis

$\dagger$ Baringochromis can be distinguished from other cichlids by the following combination of characters (Figs. 3, 4, 5, 6, 7, 8 and 9): vomer not notched; lacrimal (= IO1) with four lateral-line tubules, 
followed by five tubular infraorbitals; oral jaw teeth exclusively tricuspid or tricuspid + unicuspid; preopercle with three lateral-line tubules on lower arm; opercle and subopercle partially scaled; urohyal without anterodorsal projection; low numbers of fin spines and rays (D XI-XIII, 7-10; A III, 7-10); single or no supraneural bone; 27-29 vertebrae; cycloid scales on body and head; otoliths with prominent rostrum and antirostrum separated by deep excisura.

\section{Etymology}

From Baringo, the name of the county in which the fossils were found, and chromis (Greek), which has been applied to various colourful fish and is often used in the genus name of cichlids.

\section{Type species}

$\dagger$ Baringochromis senutae, $\mathrm{sp}$. nov.

\section{Included species}

$\dagger$ Baringochromis sonyii, sp. nov.; †Baringochromis tallamae, sp. nov.

\section{General description}

$\dagger$ Baringochromis is a medium-sized, low-bodied cichlid (Fig. 3) reaching $79.7 \mathrm{~mm}$ in standard length and $90.9 \mathrm{~mm}$ in total length. Most of the specimens are preserved in lateral view (with the head in lateral or dorso-lateral view), indicating that these fish were fairly narrow in body width compared to depth. The point of maximum body depth (31.2-45.8\% of BL) is located between the head and the origin of the pelvic fins. The minimum body depth (10.5-18.8\% of BL) is found on the posterior part of the caudal peduncle, close to the hypural plates. The depth of the head $(40.7-52.3 \%$ of $\mathrm{BL})$ is equal to or slightly exceeds the greatest body depth. The dorsal profile of the head varies due to preservation. The mouth is terminal but slightly prognathous, with the lower jaw being longer $(41.2 \pm 1.7 \%$ of HL) than the upper $(28.0 \pm 1.3 \%$ of $\mathrm{HL})$. The dorsal profile of the body is nearly straight from the supraoccipital crest to the end of the dorsal fin, and straight to slightly concave from the end of the dorsal fin to the caudal fin. The ventral profile of the body is gently curved from the lower jaw to the onset of the caudal peduncle, and straight to slightly concave along the caudal peduncle (Fig. 3). The caudal peduncle is moderately long (23.9-34.9\% of BL). Measurements (ranges and means) and meristics of the three species of $\uparrow$ Baringochromis are given in Table 1, details of all specimens are provided in the Supplementary Data.

\section{Neurocranium}

The elongated and distally widened nasal bone is preserved lateral to the premaxillary ascending spine (Figs. 4d1). The frontals are laterally compressed and elongate. The parietals are elongate, follow immediately behind the frontals, and are connected to the epiotics by the parietal crest. The supraoccipital crest is low and short, extending to the posterior border of the orbit. The orbit is rather small and nearly round (Fig. 4d1), with a vertical diameter of $10.9 \pm 1.2 \%$ of BL. The parasphenoid bisects the orbit into approximately equal parts. The suture between the parasphenoid and the vomerine wing is simple (Fig. 4c) and the vomer is not notched anteriorly (Fig. 4b). The neurocranial sensory canals are visible on the frontals. They do not seem to meet at the midline.

\section{Infraorbital series}

Six infraorbitals (io) are surrounding the orbit: the lacrimal (= io1) and io2-6; the last bone might be the dermosphenotic (Figs. 4d1, d3). The lacrimal is nearly rectangular in form, with convex ventral and posterior borders and nearly straight dorsal and anterior borders; it has four lateral-line tubules and does not overlap with io2 (Fig. 4d1, d3). Infraorbitals 2-6 appear as tubular bones with one sensory canal in the middle; io4 and io5 are elongated (Fig. 4d1, d3).

\section{Oral jaws and teeth}

The ascending arm of the premaxilla is shorter than the straight to slightly concave dentigerous arm (10.9 $\pm 2.3 \%$ BL vs. $14.0 \pm 1.6 \%$ BL; Figs. 4b, d1, e 1), with an angle of about $90^{\circ}$ between them. The maxilla is longer than the dentigerous arm of the premaxilla; its anterior margin is nearly straight, whereas the posterior margin exhibits a pointed dorsal wing (Fig. 4d1). In dorsal view the maxilla presents the premaxillad and palatinad wings of its articular head which are widely separated from each other. The dentary is short and robust (Fig. 5a). Its lower limb is longer than the upper limb and both limbs form a posteriorly open triangle into which the anterior process of the anguloarticular inserts (Fig. 5a). Teeth can be discerned on the first two-thirds of the dentary. The anguloarticular is slightly longer than deep (Figs. 4d1, 5a), with a 
pointed, dorsally directed primordial process. The ventralmost part of the anguloarticular is longer vertically than horizontally and is closely associated with the small retroarticular (Figs. 4d1, 5a). The oral jaws bear relatively large robust tricuspid and/or unicuspid teeth in the outer row (Fig. 8b, g-i, l) and slightly to distinctly smaller tricuspid and/or unicuspid teeth in the inner rows (Fig. 8a, c, j, k, n-r); it is not possible to discern the exact number of inner tooth rows, but at least two rows are present (Fig. 8a, c).

\section{Suspensorium and opercular apparatus}

The quadrate is triangular with a convex posterior margin (Figs. 4d1, 5a). Its condyle is anteroventrally directed and articulates with the articular facet of the anguloarticular (Fig. 5a). The symplectic is a narrow, posteriorly broadening and laminar bone, that contacts the quadrate ventrally and extends posteriorly almost as far as the hyomandibula (Figs. 4d1, 5d). The palatine is connected to the slender and pointed ectopterygoid and displays a $155^{\circ}$ angle between its anterior and ventroposterior arms (best in specimen OCO-5-31(2); Fig. 4c). The L-shaped preopercle has an elongated and dorsally pointed vertical arm, whereas its horizontal arm is much shorter and broader; the posteroventral corner is rounded and forms an approximately $90^{\circ}$ angle (Fig. 4d1). It presents a branched sensory canal with two terminal and four medial tubules, whereof three tubules are situated on the horizontal arm (Fig. 4d1-2). The hyomandibula is found dorsal to the tip of the preopercle and extends to the middle of the vertical arm of it (Fig. 4d1). The opercle is almost triangular in shape, with a pointed anteroventral corner, which is in contact with the subopercle (Fig. 5c). Its anterior and dorsal margins are convex and the anterior margin ends in a pointed anterodorsal process, whereas the posterior margin is slightly S-shaped (Fig. 5c). The subopercle has a curved ventral margin and a prominent pointed ascending process anteriorly (Fig. 5b), projecting between the opercle and preopercle (Fig. 5c). The interopercle is an elongated and slender element with rounded anterior and posterior ends.

\section{Hyoid and branchial arches}

The ceratohyal bears five branchiostegal rays, of which the first is attached to the slender part of the anterior ceratohyal, followed by three rays attached to the broader part of the anterior ceratohyal and the last one is attached to the posterior ceratohyal (Fig. 5d). Anterior to the ceratohyal, the ventral hypohyal and the dorsal hypohyal are recognizable (Fig. 5e). The urohyal is robust, posteriorly widening and lacks an anterodorsal projection (Fig. 5f1, f2).

The teeth on the pharyngeal bones are bicuspid, with a prominent and slightly recurved major cusp and a small minor cusp, or shoulder. In specimen OCO-58/23(7) the pharyngeal jaws are partially preserved, but their outline is unclear.

\section{Vertebral column}

The vertebral column is gently curved (Fig. 3) and contains a total of 27-29 vertebrae; $13-15$ of them are abdominal and 13-15 caudal (see Table 1). All vertebral centra bear a longitudinal lateral ridge (Fig. 3). The last two vertebrae are short. The first, and in some cases the second neural spine project in front of the first dorsal pterygiophore. The neural spines are short at the beginning of the vertebral column, gradually increase in length towards the end of the spinous part of the dorsal fin and shorten again along the caudal peduncle (Fig. 3a-c). There are 11-13 pairs of robust ribs, which reach the margin of the abdominal cavity and are connected to the centra by strong parapophyses. The first pair of ribs originates on the third vertebra. Either none or a single supraneural bone is present between the supraoccipital and the first pterygiophore. Epineurals are recognizable as thin rod-shaped parallel imprints on the upper third of the ribs. Black organic remains are recognizable underneath the tips of the ribs until the origin of the anal fin, which might be the remains of the abdominal cavity or stomach contents (Fig. 3c).

\section{Pectoral girdle and fins}

The cleithrum is elongate and curved, with a lamellar posterior projection and a pointed ventral end (Fig. 6a). A small and pointed process is present at the posteroventral extension (Fig. 6a). The dorsal process is pointed, but in most cases it is overlain by the elongated and slender supracleithrum. The posttemporal is bifurcated, with the upper limb thinner than, but approximately as long as the lower (Fig. 6a). The scapula is rectangular with a central scapular foramen and supports the upper two proximal radials of the pectoral fin (Fig. 6a). The coracoid is coneshaped, tapers rostrally and supports the lower two of the four rectangular proximal radials. The uppermost 
Table 1 Morphometric measurements and meristic counts of the three new species of $\dagger$ Baringochromis from Waril (this study) and the earlier described haplochromine $\dagger$ Warilochromis unicuspidatus from the same locality (Altner et al., 2020)

\begin{tabular}{|c|c|c|c|c|c|c|c|}
\hline \multicolumn{2}{|c|}{$\dagger$ †. senutae $\mathrm{sp}$. nov } & \multicolumn{2}{|c|}{$\dagger B$. sonyii $\mathrm{sp}$. nov. } & \multicolumn{2}{|c|}{$\dagger$ †. tallamae sp. nov. } & \multicolumn{2}{|c|}{$\dagger W$. unicuspidatus } \\
\hline \multicolumn{2}{|l|}{$\mathrm{BL}(\mathrm{mm})$} & \multicolumn{2}{|c|}{$37.4 \pm 1.9(35.4-39.7)(n=5)$} & \multicolumn{2}{|c|}{$30.8 \pm 5.5(26.9-34.7)(n=2)$} & \multicolumn{2}{|c|}{$45.9(n=1)$} \\
\hline$\% \mathrm{BL}$ & \multicolumn{2}{|l|}{ Mean \pm SD (range) } & \multicolumn{2}{|l|}{ Mean \pm SD (range) } & \multicolumn{3}{|l|}{ Mean \pm SD (range) } \\
\hline Total length & $\begin{array}{c}179.8 \pm 8.2(164.6-1 \\
13)\end{array}$ & 7.6) $(n=$ & $\begin{array}{l}163.9 \pm 5.0(158.5-16 \\
3)\end{array}$ & 3.2) $(n=$ & $\begin{array}{l}174.6 \pm 4.9(169.7-179 . \\
2)\end{array}$ & 5) $(n=$ & 178.4 \\
\hline Standard length & \multicolumn{2}{|c|}{$\begin{array}{l}154.8 \pm 3.7(149.6-164.0)(n= \\
13)\end{array}$} & \multicolumn{2}{|c|}{$\begin{array}{l}139.7 \pm 3.8(136.4-144.7)(n= \\
4)\end{array}$} & \multicolumn{2}{|c|}{$\begin{array}{l}150.2 \pm 2.9(147.3-153.1)(n= \\
2)\end{array}$} & 150.1 \\
\hline Head length & \multicolumn{2}{|c|}{$54.6 \pm 3.3(49.3-62.1)(n=13)$} & \multicolumn{2}{|c|}{$38.4 \pm 2.6(35.1-40.5)(n=4)$} & \multicolumn{2}{|c|}{$51.6 \pm 1.5(50.1-53.1)(n=2)$} & 49.9 \\
\hline Head depth & \multicolumn{2}{|c|}{$47.1 \pm 3.3(41.5-51.6)(n=10)$} & \multicolumn{2}{|c|}{$41.6 \pm 1.3(40.7-43.5)(n=4)$} & \multicolumn{2}{|c|}{$49.8 \pm 2.5(47.3-52.3)(n=2)$} & 50.8 \\
\hline Orbit & \multicolumn{2}{|c|}{$11.7(n=1)$} & \multicolumn{2}{|c|}{-} & \multicolumn{2}{|c|}{$7.9(n=1)$} & - \\
\hline Maximum body depth & \multicolumn{2}{|c|}{$39.5 \pm 4.3(32.2-44.5)(n=11)$} & \multicolumn{2}{|c|}{$36.8 \pm 3.6(31.2-40.8)(n=5)$} & $43.1 \pm 2.7(40.3-45.8)$ & $(n=2)$ & 47.3 \\
\hline $\begin{array}{l}\text { Depth of body at } \\
\text { anal fin origin }\end{array}$ & $27.5 \pm 3.6(23.5-34.8$ & $(n=12)$ & $25.2 \pm 3.4(20.6-29.0$ & $(n=5)$ & $35.3 \pm 2.4(32.9-37.7)$ & $(n=2)$ & 42.6 \\
\hline Minimum body depth & $14.8 \pm 1.5(12.8-17.5$ & $(n=13)$ & $14.1 \pm 2.2(10.5-16.2)$ & $(n=5)$ & $18.8(n=1)$ & & 18.7 \\
\hline $\begin{array}{l}\text { Length of dorsal fin } \\
\text { base }\end{array}$ & $65.6 \pm 2.6(60.3-70.1$ & $(n=10)$ & $60.8 \pm 3.3(55.8-62.7)$ & $(n=4)$ & $72.5(n=1)$ & & 67.8 \\
\hline Length of anal fin base & $20.2 \pm 1.8$ & $(n=11)$ & $18.2 \pm 1.9(16.1-20.2)$ & $(n=5)$ & $17.7 \pm 0.2(17.5-17.9)$ & $(n=2)$ & 26.4 \\
\hline $\begin{array}{l}\text { Length of pelvic fin } \\
\text { base }\end{array}$ & $21.8 \pm 2.7(16.3-24.5$ & $(n=7)$ & $22.0 \pm 3.3(18.9-21.7)$ & $(n=3)$ & - & & 7.6 \\
\hline Caudal fin length & $32.2 \pm 2.8(28.5-35$. & $(n=7)$ & $26.1 \pm 4.6(22.0-31.0$ & $(n=3)$ & $31.6(n=1)$ & & 34.9 \\
\hline $\begin{array}{l}\text { Length of ascending } \\
\text { arm of premaxilla }\end{array}$ & $10.3 \pm 1.9(7.1-13.1)$ & $(n=8)$ & $10.9 \pm 1.1(10.1-11.7$ & $(n=2)$ & $14.1 \pm 0.6(13.5-14.7)$ & $(n=2)$ & 12.2 \\
\hline $\begin{array}{l}\text { Length of dentigerous } \\
\text { arm of premax }\end{array}$ & $14.6 \pm 1.4(12.3-16.6$ & $(n=7)$ & $12.1 \pm 0.9(11.5-12.7)$ & $(n=2)$ & $13.5(n=1)$ & & 15.7 \\
\hline Length of lower jaw & $21.1 \pm 2.2$ & $(n=10)$ & $15.8 \pm 0.5(15.4-16.1)$ & $(n=2)$ & $22.4 \pm 1.1(21.3-23.5)$ & $(n=2)$ & 21.4 \\
\hline $\begin{array}{l}\text { Length of caudal } \\
\text { peduncle }\end{array}$ & $30.5 \pm 2.1(26.2-32.4$ & $(n=11)$ & $30.9 \pm 2.3(27.7-33.1)$ & $(n=4)$ & $29.4 \pm 5.5(23.9-34.9)$ & $(n=2)$ & 29.2 \\
\hline $\begin{array}{l}\text { Length of ventral } \\
\text { spine }\end{array}$ & $18.1 \pm 1.7(14.1-20.4$ & $(n=11)$ & $16.5 \pm 1.7(13.8-18.3$ & $(n=5)$ & $17.2 \pm 1.5(15.7-18.7)$ & $(n=2)$ & 21.8 \\
\hline Meristics & & & & & & & \\
\hline $\begin{array}{l}\text { Dorsal fin spines } \\
\text { and rays }\end{array}$ & XI-XIII, 7-10 & & XII-XIII, 9 & & XIII, 8-9 & & XIV, 10 \\
\hline $\begin{array}{l}\text { Anal fin spines } \\
\text { and rays }\end{array}$ & III, 7-10 & & III, 8-9 & & III, 7-8 & & III, 9 \\
\hline Pelvic fin & I, 5 & & I, 5 & & I, 5 & & I, 5 \\
\hline Pectoral fin & $\min .12$ & & $14-15$ & & 15 & & - \\
\hline Vertebrae & $27-28(13-15+13-$ & & $28-29(14-15+14-$ & & $28(14-15+13-14)$ & & $\begin{array}{l}33(19+ \\
14)\end{array}$ \\
\hline VtPtLDs & $11-13$ & & $12-14$ & & 12 & & 17 \\
\hline Caudal fin & $4-7,8+8,3-7$ & & $2-7,8+8,5-7$ & & $5,8+8,7$ & & $4,8+8,5$ \\
\hline
\end{tabular}

Data refer to body length (BL) and mean values \pm standard deviation and ranges in \% of BL. See Supplementary Data for details of all specimens. $n$ number of specimens, VtPtLDs ordinal number of the vertebra associated with pterygiophore of last dorsal fin spine

of the proximal radials is the smallest and the lowermost the largest (Fig. 6b). The pectoral fin has 13-15 rays, whereof the fourth from the top seems to be the longest and the following rays diminish continuously in size, giving this fin a pointed shape. 


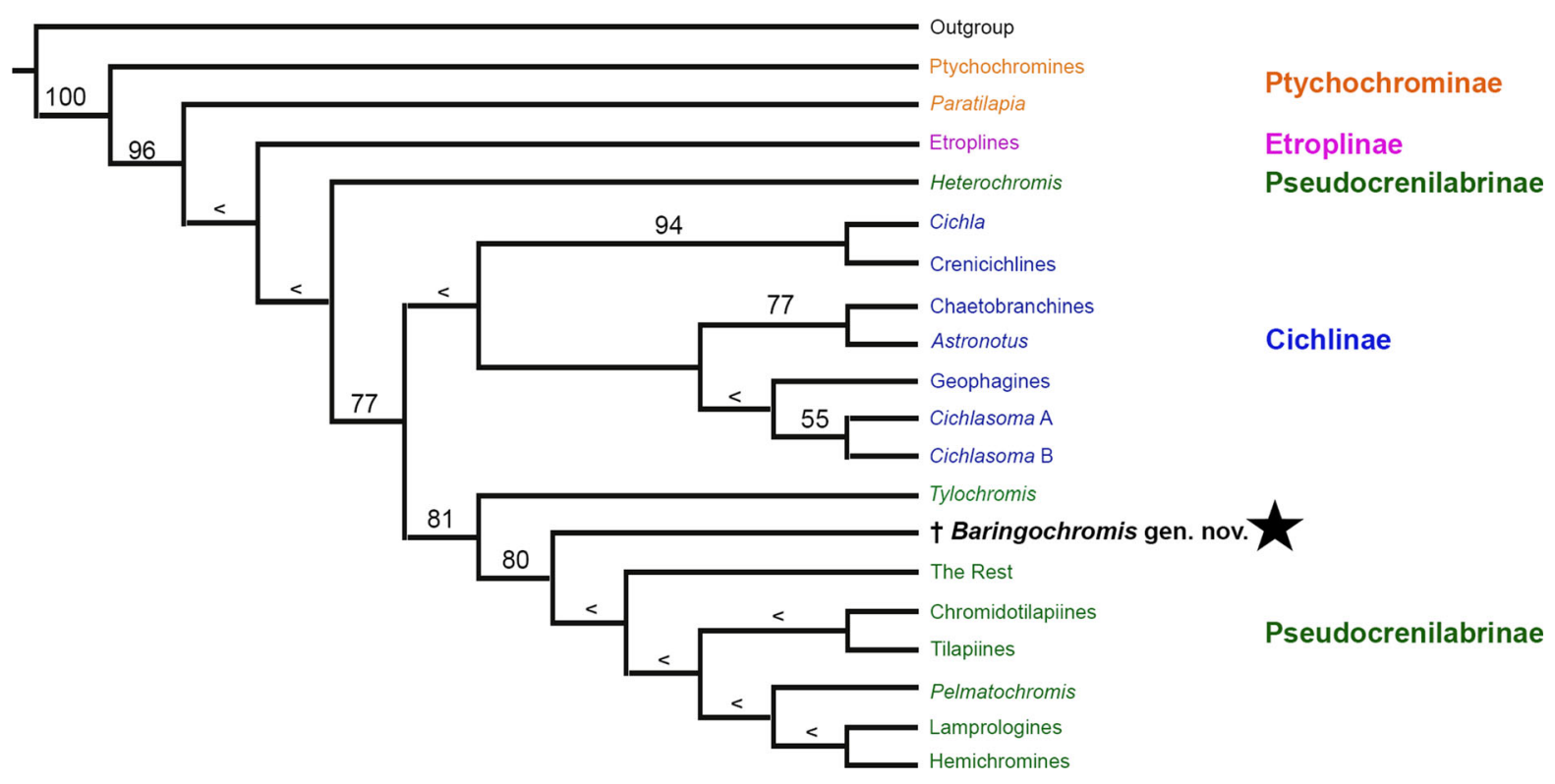

Fig. 2 Phylogenetic position of $\dagger$ Baringochromis gen. et $s p$. nov. (indicated with star) among the four cichlid subfamilies based on the slightly modified morphological data matrix of Stiassny (1991) (see Methods for details). This is the single most parsimonious tree produced by TNT (implied weights, $K=12$ ),

\section{Pelvic girdle and fins}

The basipterygia are triangular and anteriorly tapered (Fig. 6c). The pelvic fin has one spine and five rays (Fig. 6c), none of which reach the anal fin (Figs. 3a). Which of the rays is the longest cannot be stated with certainty.

\section{Dorsal fin}

The dorsal fin consists of 11-13 spines and 7-10 branched rays (Table 1), with the spiny and soft dorsal fin portions being continuous (Fig. 3c, d). The spiny dorsal fin base is up to three times longer than the rayed one (Fig. 3a-c, e). The anteriormost spines increase in length from the first to the last. They are followed by segmented rays, which are longer than the spines (Fig. 3c). Each spine and ray is supported by a thin and elongate pterygiophore, with exception of the last ray, which can be autogenous. The anterior pterygiophores are associated with their individual interneural space, whereas two pterygiophores enter the interneural space posteriorly (last rays). The first pterygiophore inserts into the interneural space between vertebrae 1 and 2 or 2 and 3, while the last pterygiophore associated with a dorsal spine inserts behind the neural spine of vertebra $11,12,13$ or 14 tree length $=34$ steps, consistency index $=0.85$, retention index $=0.93$. Bootstrap values from 1000 pseudoreplicates are presented on the branches. The arrowhead symbols $(<)$ indicate values below 50\%. Eight (out of 28) characters were coded for $\dagger$ Baringochromis gen. nov.

(see character VtPtLDs in Table 1). The pterygiophores associated with the rays gradually shorten towards the caudal fin (Fig. 3b, c).

\section{Anal fin}

The anal fin originates far behind the dorsal fin origin approximately at the height of the last dorsal fin spine (Fig. 3). It consists of three spines and 7-10 branched and segmented rays (Table 1), which are longer than the spines. The two anteriormost fin spines are supported by one pterygiophore, while the third spine and the branched rays are each associated with a single pterygiophore, though the last ray can be autogenous. The first pterygiophore is associated with the haemal spine of the first caudal vertebra or the ribs of the last abdominal vertebra. The anal fin spines increase in length posteriorly, the third being the longest (2.1-2.6 times the length of the first). The first three branched rays are the longest ones; they gradually diminish in size, as do the pterygiophores (Fig. 3c).

\section{Caudal skeleton and fin}

The caudal axial skeleton includes five hypural plates, a parhypural, two epurals, one uroneural, and 
two or three preural vertebrae (Fig. 6d1, d2). Hypural plates 1 and 2 and hypural plates 3 and 4 can either be fused or be separated by a suture. In the latter case, hypural plate 1 is always larger than hypural 2 and hypural 4 is always larger than hypural 3. Hypural 5 is slender and always separate from hypural 4 . It extends into the space between the terminal centrum and the uroneural. The diastema is small, ranging from 0.4 to $0.6 \mathrm{~mm}$ in depth. The parhypural is broad and its distal section lies close to hypural 1 ; it can either be isolated from, or make contact with the terminal centrum, and displays a short, posteriorly directed hypurapophysis
Fig. 4 Neurocranium, infraorbital series, suspensorium and hyoid arch of $\dagger$ Baringochromis. a1 head of $\dagger B$. sonyi sp. nov. (paratype OCO-5-4) in dorsolateral view showing epiotics, frontals, neurocranial lateral line canals, and parietals, a2 reconstruction of the neurocranium in dorsal view, $\mathbf{b}$ close up of parasphenoid and vomer of $\dagger$ B. senutae sp. nov. (holotype OCO5-29R(1), ventral view), showing vomer without anterior notch; c close up of parasphenoid and vomer of $\dagger B$. sp. (OCO-5-31(2), lateral view), showing simple suture between both bones, d1 overview of head of $\dagger B$. sp. (OCO-5-43) showing opercle, subopercle, preopercle, infraorbital series, dentary, angular, premaxilla, $\mathbf{d} \mathbf{2}$ reconstruction of preopercle, $\mathbf{d} \mathbf{3}$ reconstruction of infraorbital series with lacrimal with four lateral-line tubules followed by five tubular infraorbitals (io 2-6). For the abbreviations of the bones see "Materials and methods"
Fig. 3 Species of $\dagger$ Baringochromis, lateral view. a holotype of $\dagger B$. senutae sp. nov. (OCO-529-R(1)), b paratype of $\dagger B$. senutae sp. nov. (2014-Wa8(2)), c paratype of $\dagger B$. sonyii sp. nov. (OCO-537(1)), d holotype of $\dagger B$. sonyii sp. nov. (OCO-529(1), mirrored for better comparison), e holotype of $\dagger$ B. tallamae sp. nov. (2014WA-24b)
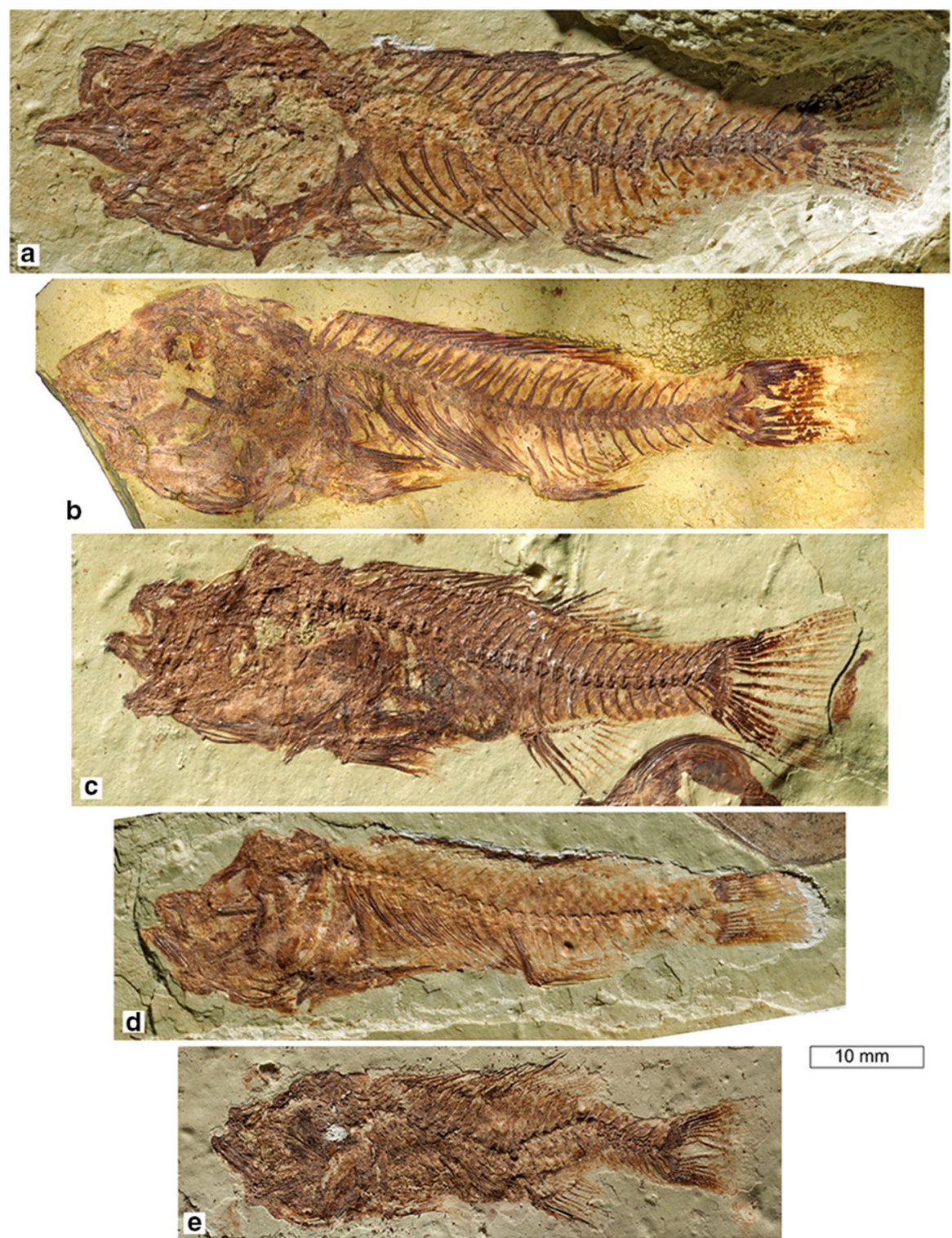

$10 \mathrm{~mm}$ 

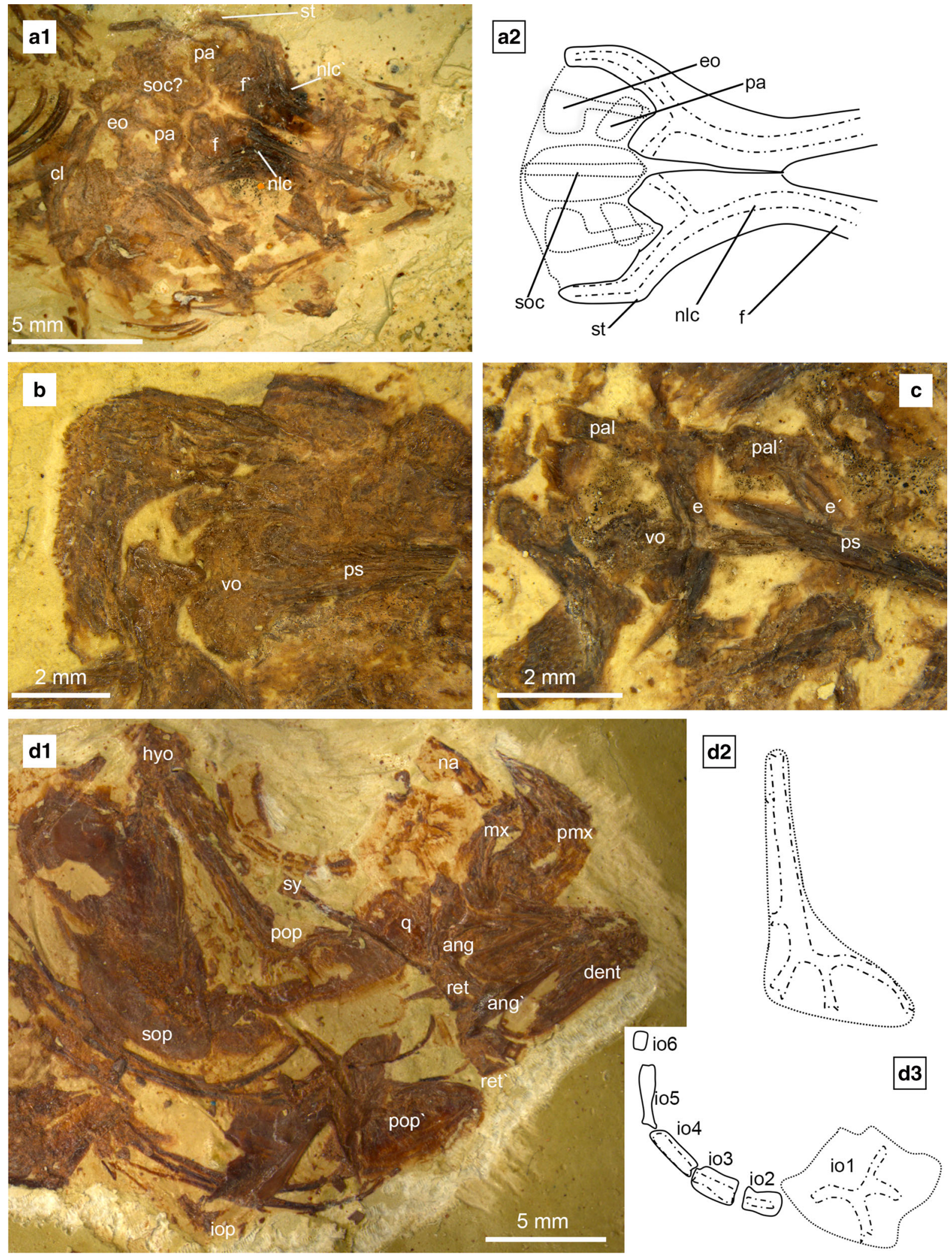

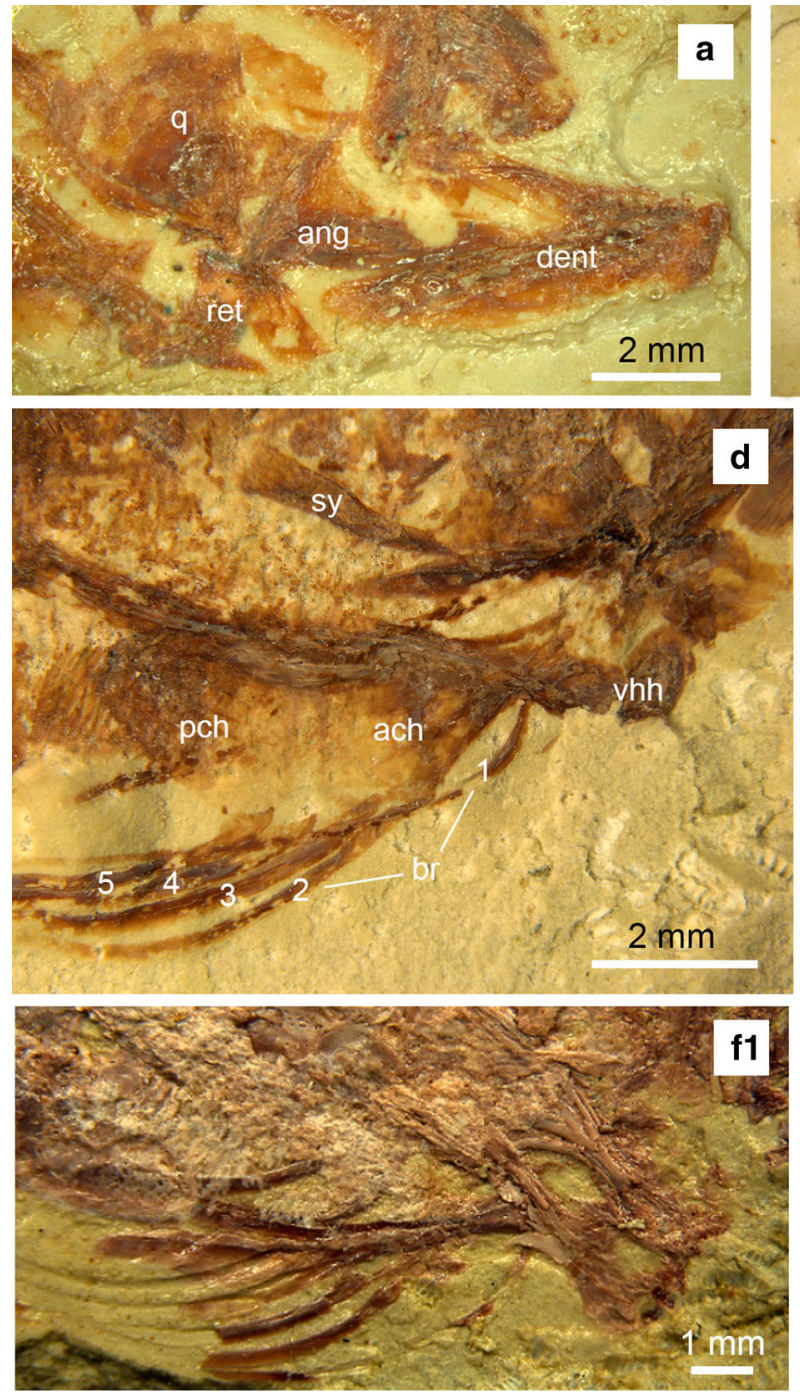

Fig. 5 Details of the head and hyoid arch of $\dagger B$. senutae sp. nov. (a-d, f) and $\dagger$ Baringochromis sp. (e). a Close up of lower jaw with anguloarticular, retroarticular and quadrate (OCO-51(1)), b isolated subopercle (OCO-5b-10(1)), c close up of squamation on opercle and subopercle (OCO-5-42(2), opercular spot indicated with dotted line), d, close up of hyoid arch with

on its proximal part (Fig. 6d1, d2). The uroneural is long (third the length of the neural spine of preural vertebra 3 ) and extends between the second epural and hypural 5. Two elongate epurals of equal length and width are aligned in parallel between the uroneural and the distinctively elongated neural spine of preural vertebra 3 (Figs. 6d1, d2, 7a). Preural vertebra 2 lacks a neural spine, while the neural arch is present. The terminal centrum is approximately triangular in shape, and extends posteriorly between hypurals 4 and 5 .
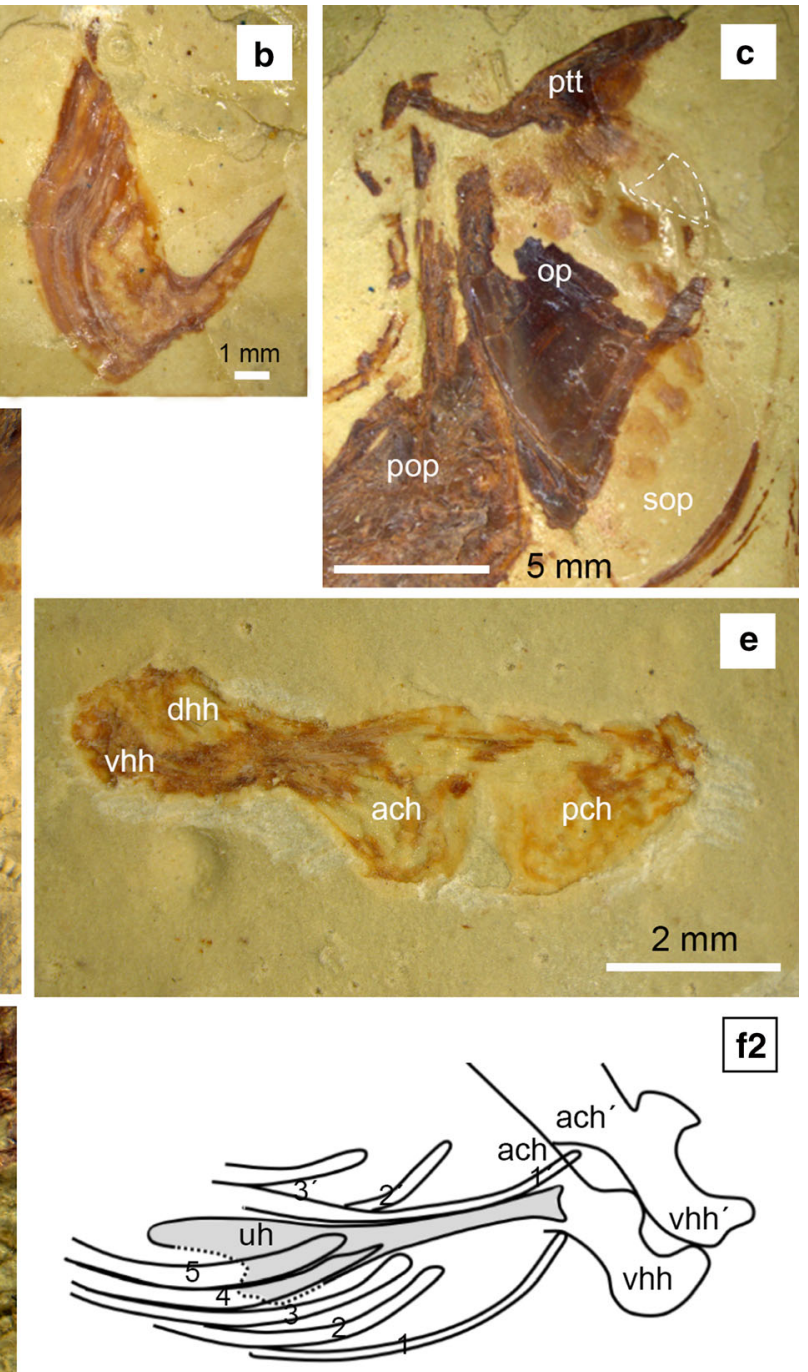

five branchiostegal rays (2014-WA-11-R(1)), e, isolated hyoid arch with dorsal hypohyal preserved (2014-WA-11(5)), f1, f2 photo and reconstruction of hyoid arch showing urohyal (grey) without anterior projection (2014-WA-7-R(2)). For the abbreviations of the bones see "Materials and methods"

The caudal fin has a slightly rounded to truncated posterior margin (Fig. 3) and is made up of 16 (8 dorsal +8 ventral) principal rays and 2-7 dorsal and 3-7 ventral procurrent rays. The principal caudal rays are aligned without interruption and supported by the parhypural, the epurals and the five hypurals.

\section{Squamation}

Relatively large (1.3-1.6 mm height, $1.5-2.1 \mathrm{~mm}$ width), ovate cycloid scales cover the body (Fig. 7a- 

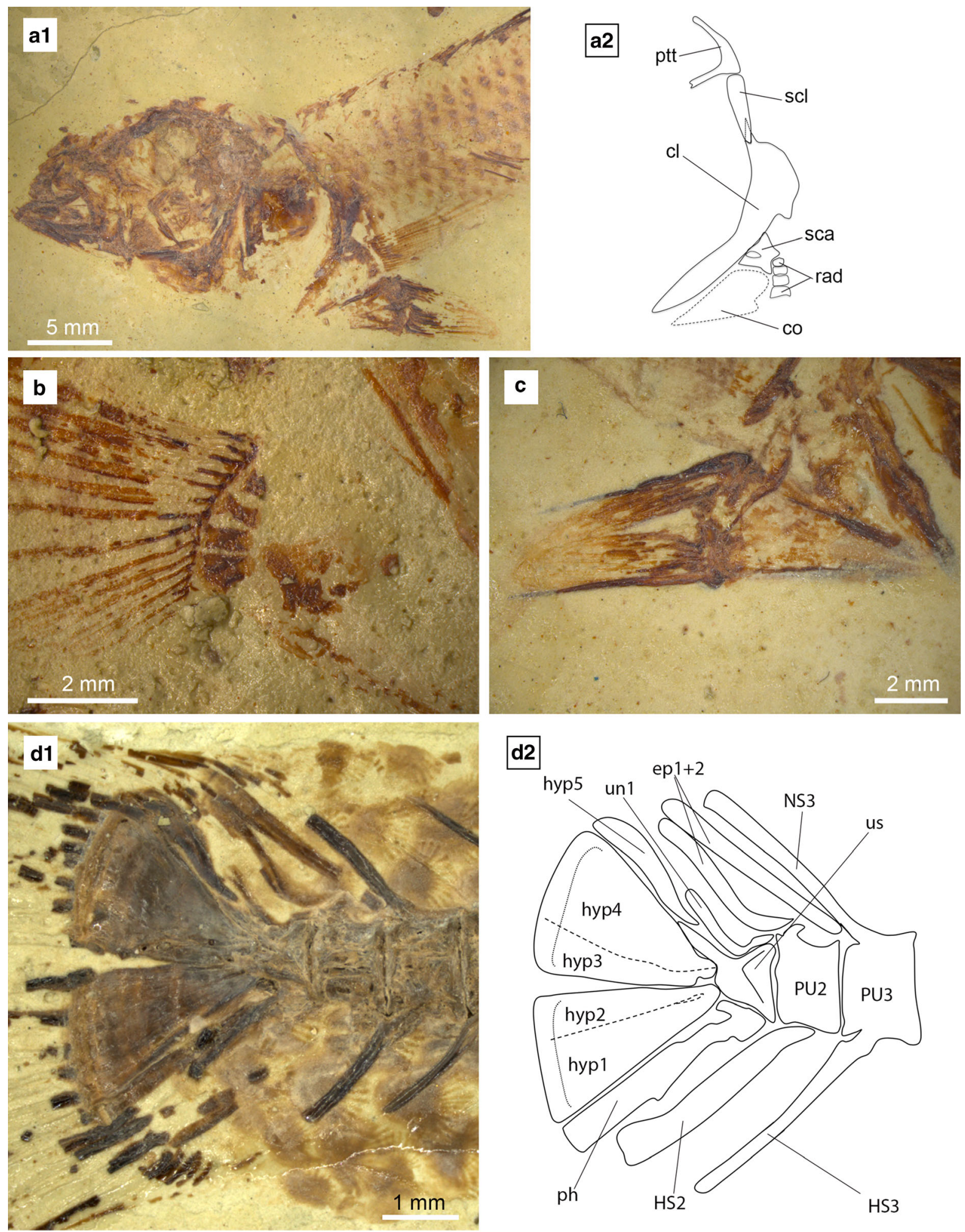
४Fig. 6 Pectoral and pelvic girdle and caudal skeleton of $\dagger$ Baringochromis. a1, a2 photo and reconstruction of pectoral girdle $(\dagger B$. sp., OCO-5-21(1)); b pectoral fin showing 14 rays and four proximal radials ( $\dagger B$. senutae sp. nov., OCO-5$38 \mathrm{R}(5))$; c pelvic girdle and fins ( $\dagger B$. sp., OCO-5-15(1)); d1-2 caudal skeleton showing hypural plates 1 and 2 , and 3 and 4 separated by a suture $(\dagger B$. sp., OCO-5-5(2)). For the abbreviations of the bones see "Materials and methods"

d). Also the opercle bears large cycloid scales. The subopercle is covered by a single row of large cycloid scales, its ventral part is scaleless (Fig. 5c). The preopercle and the interopercle appear to be scaleless. Weak imprints of small belly scales are recognizable in one specimen of $\dagger B$. sonyii sp. nov. (OCO-5-37/ 42(1); Fig. 3c), other specimens do not show scales in the belly region.
As is typical for cichlids, the lateral line is divided into two parts (Fig. 7c, d). The origin of the anterior lateral line segment is not recognizable, but it seems to consist of approximately 15 scales (not all of which are pored) with the posterior end located approximately above the 20th vertebra. There is a gap of two scale rows between the anterior and posterior lateral line segments, while 1.5 to two scale rows lie between the anterior lateral line segment and the dorsal fin (Fig. 7c, d). The posterior lateral line segment (consisting of 10 to 12 scales with tubular sensory opening or simple pore) continues approximately opposite to or slightly behind the end of the anterior lateral line segment and runs either above, below, or on the vertebral column (Fig. 7c, d). The flank scales show up to 12 radii (Fig. 7a-d).
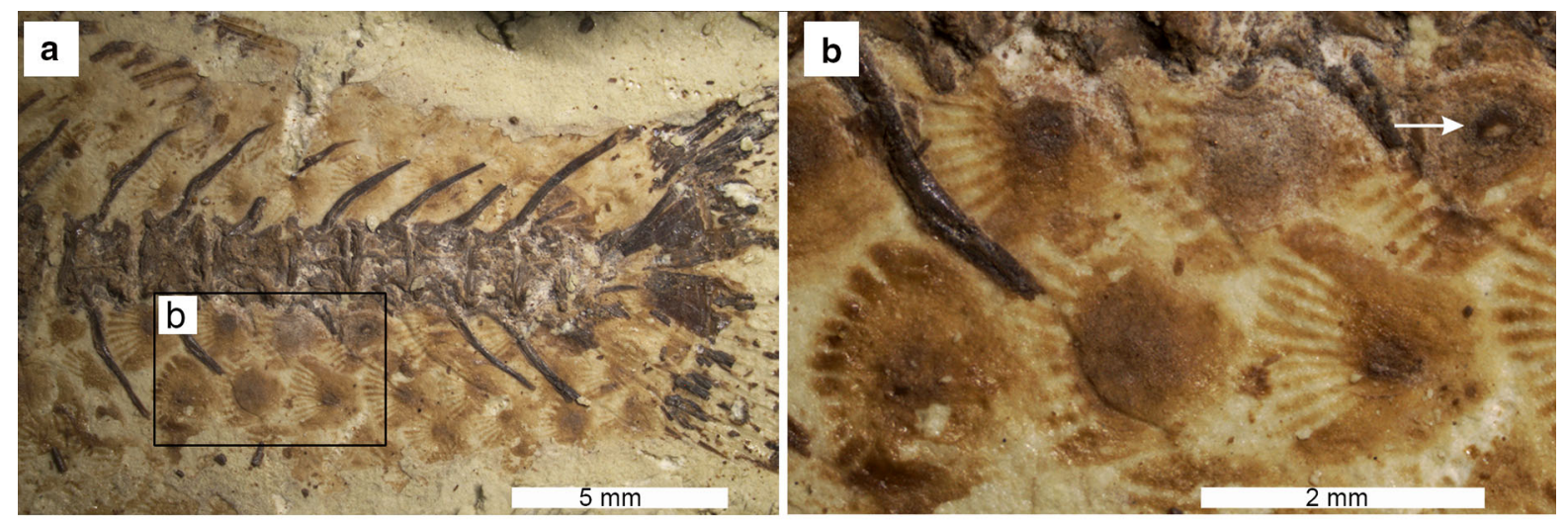

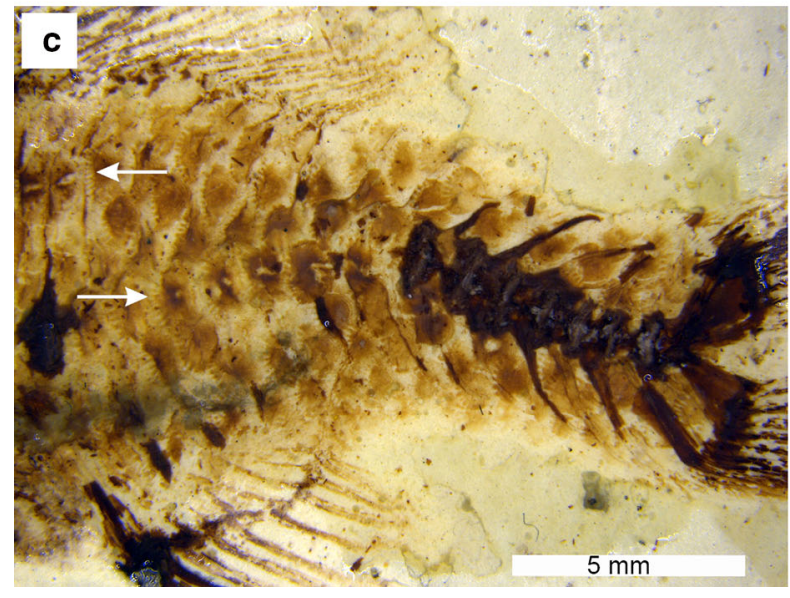

Fig. 7 Squamation and lateral line of $\dagger$ Baringochromis. a, b flank and caudal peduncle of $\dagger B$. senutae sp. nov. (holotype, OCO-5-29-R(1)) showing large cycloid scales with prominent radii (arrow in $\mathrm{b}$ depicts sensory pore of the lower lateral line

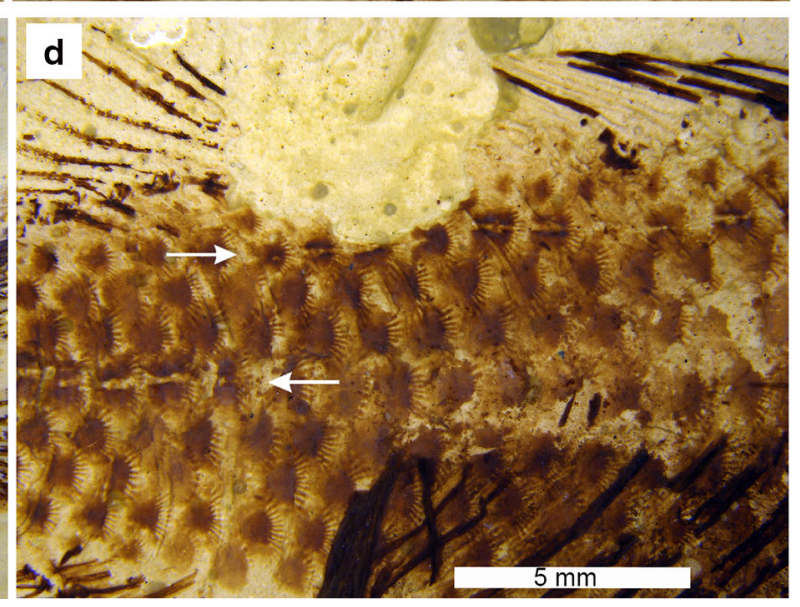

segment), $\mathbf{c}$ flank and caudal peduncle of $\dagger B$. tallamae sp. nov. exhibiting upper and lower lateral line (holotype, 2014-WA-24), d flank of $\dagger B$. sonyii sp. nov. exhibiting upper and lower lateral line (paratype, OCO-5-42(1)) 
$\dagger B$. senutae sp. nov.
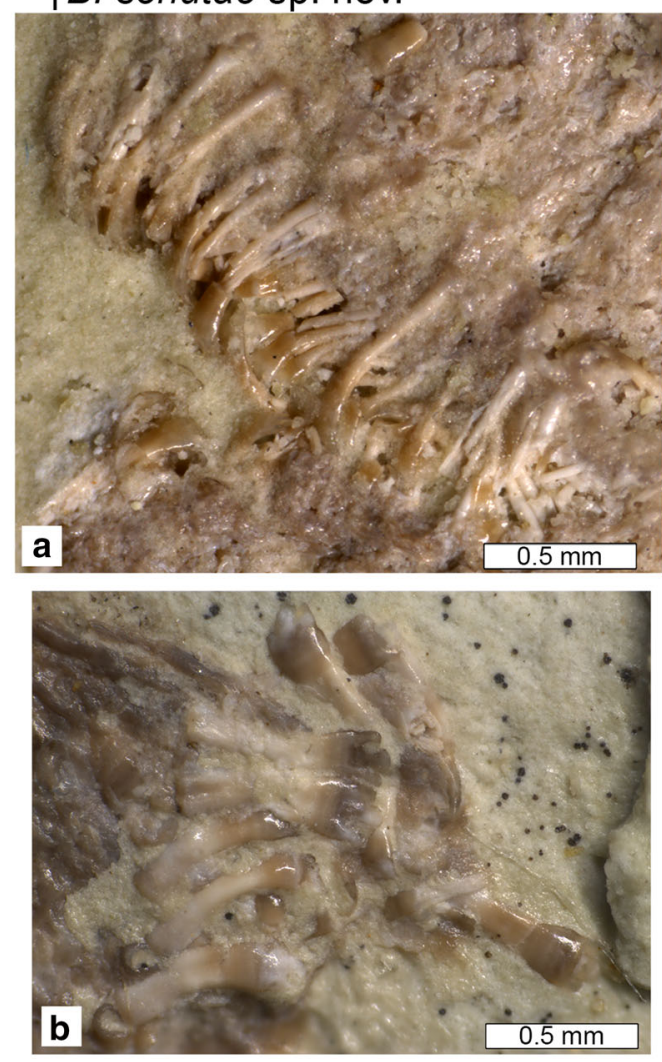
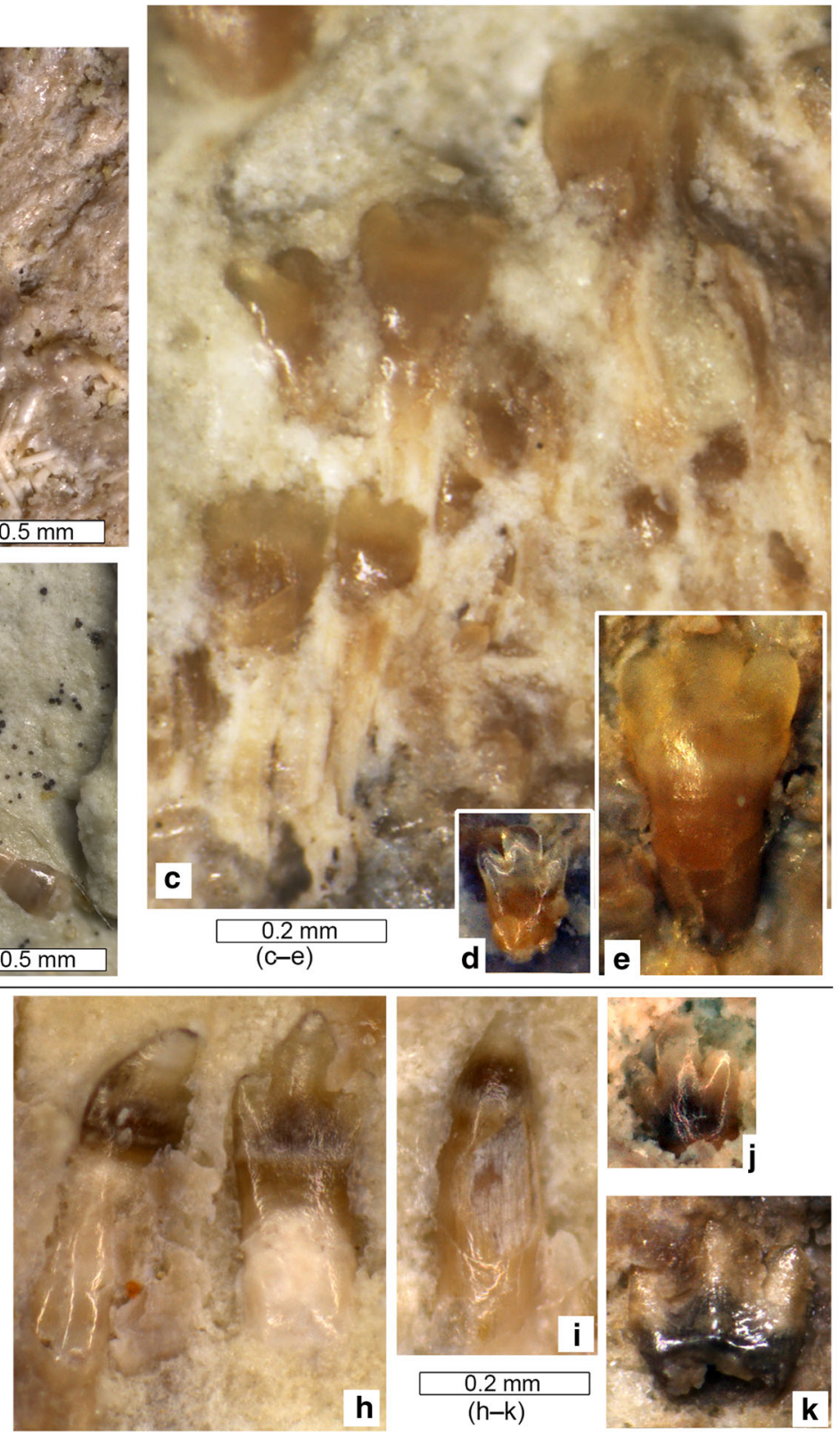

$\dagger B$. sonyii sp. nov.

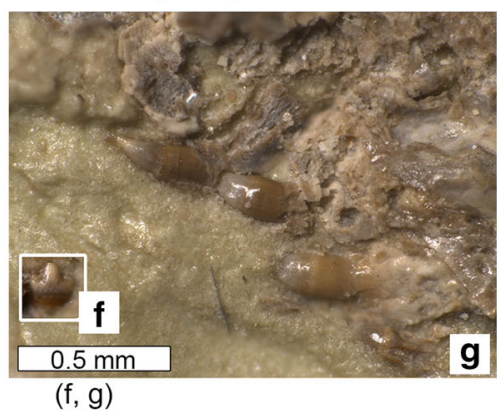

†B. tallamae sp. nov.
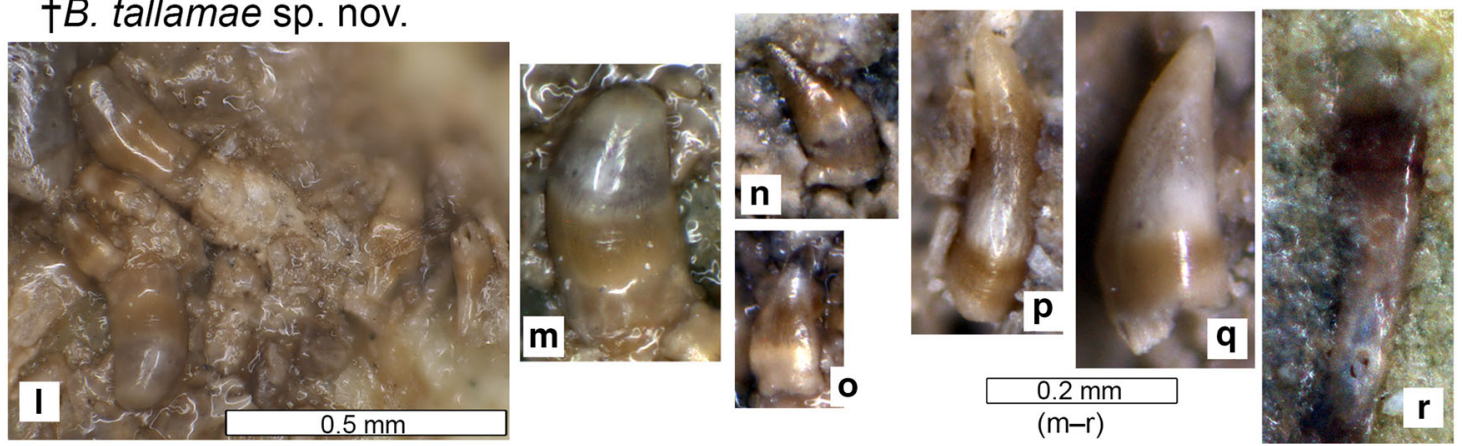
४Fig. 8 Oral jaw dentition of $\uparrow$ Baringochromis. a Multiple rows of elongated, slender tricuspid teeth from the oral jaws of $\dagger B$. senutae sp. nov. (paratype, 2014-Wa-8), b large, robust tricuspid teeth at the anterior tip of the premaxilla of $\dagger B$. senutae sp. nov. (paratype, 2014-Wa-20b(1)), c two rows of long tricuspid teeth of the dentary of $\dagger$ B. senutae sp. nov. (paratype, OCO-5-19), d, e small tricuspid tooth with relatively elevated middle cusp (d, OCO-5-20(1)) and large tricuspid tooth with relatively low middle cusp of $\dagger B$. senutae sp. nov. (e, 2014-WA-7-R(2)), f, g small tricuspid tooth with elevated middle cusp (f) and conical to cone-shaped unicuspid teeth $(\mathrm{g})$ from the posterior part of the premaxilla of $\dagger B$. sonyii sp. nov. (OCO-5-23(6)), $\mathbf{h}-\mathbf{j}$ large unicuspid and tricuspid (h), large conical (i), and medium-sized tricuspid tooth (j) from the anterior part of the premaxilla of $\dagger B$. sonyii sp. nov. (paratype, OCO-5-16(4)), $\mathbf{k}$ large tricuspid tooth from the anterior part of the premaxilla of $\dagger B$. sonyii sp. nov. (holotype, OCO-5-29(1)), l-q different unicuspid teeth from the anterior part of the premaxilla of $\dagger B$. tallamae sp. nov. (holotype, 2014-Wa-24b), $\mathbf{r}$ tricuspid tooth from the premaxilla of $\dagger B$. tallamae (paratype, 2014-Wa-10)

\section{Otoliths}

A pair of saccular otoliths was found in an isolated head of $\dagger$ Baringochromis senutae sp. nov. (specimen OCO-5-23-R(2), Fig. 9b). The otoliths are of elliptical shape and have smooth to slightly crenate margins. The inner face is planar to very slightly convex and the outer face is almost planar. A prominent and pointed rostrum and a much shorter antirostrum is present, with a deep excisura between them. The ventral margin is slightly curving, the posterior margin is round to blunt, and the dorsal margin has a median tip with a slight indentation behind it. The sulcus is in median position; it first runs straight before curving downwards in its posterior section. The ostium is narrow and deep, the cauda less narrow, but still deep. An anterocaudal pseudocolliculum is recognizable. The crista inferior is weak, whereas the crista superior is high and sharp along the ostium and the cauda, with the exception of the posteriormost segment of the cauda. The crista inferior is very thin. The ventral line is relatively high set.

\section{$\dagger$ Baringochromis senutae Altner \& Reichenbacher, sp. nov.}

(Figures 3a, b, 4b, 5a-d, f, 6b, 7a, b, 8a-e, 9b)

\section{Holotype \\ OCO-5-29-R(1)}

\section{Paratypes}

16 skeletons, numbered with OCO-5-\# and -5b-\# (field work in 2013) and 2014-Wa-\# (field work in
2014). (\#) indicates an individual specimen when more than one specimen is preserved on the same slab; $\mathrm{a} / \mathrm{b}$ refers to part and counterpart; $\mathrm{R}$ indicates reverse (back side) of slab.

Specimens with prefix OCO-5-: 1/6(1), 8/23(3), 10/12(1), 13(1), 19, 38(6), 40(6).

Specimens with prefix OCO-5b-: 5(1), 8, 10(1).

Specimens with prefix 2014-WA-: 2a/b(1), 8(2), 9(1), 19(1), 20a/b(1), 21a/b(1).

\section{Further material}

Remains of 47 skeletons with preserved head and oral jaw dentition.

Specimens with prefix OCO-5-: 1-R(1), 6-R(1), 5(1), 5-R(1), 8-R(2), 15(7), 19, 19-R, 20(1), 23-R(1), 23-R(2), 26(4), 28(5), 31(3), 31-R(2), 35-R, 37/42(2), 38(3)，38-R(3)，38-R(5)，39-R，42-R(1)，43-R(1), 43-R(4).

Specimens with prefix OCO-5b-: 1a/b, 9(3), 9(5), 10(2).

Specimens with prefix 2014-WA-: 1a/b(1), 2a$\mathrm{R}(3), 3(4), 6,7(3), 7-\mathrm{R}(2), 7-\mathrm{R}(3), 10(1), 11-\mathrm{R}(1)$, 12(1), 12(3), 17(2), 20a(6), 20a-R, 20a/b(2), 20a/b(7), 20b(6), 25(3), 25(4).

\section{Etymology}

Named in honour of Prof. Dr. Brigitte Senut, Paris (France), for her dedicated research in the field of human evolution and palaeoanthropology on the African continent, and for her continuous kind support of this research project.

\section{Type locality and age}

Outcrop Waril $\left(0^{\circ} 40^{\prime} 56.21^{\prime \prime} \mathrm{N} 35^{\circ} 43^{\prime} 7.43^{\prime \prime} \mathrm{E}\right)$ in Central Kenya (Fig. 1); upper Miocene (9-10 MYA).

\section{Differential diagnosis}

$\dagger$ Baringochromis senutae sp. nov. differs from the two other species of $\uparrow$ Baringochromis by its oral dentition, which consists of exclusively tricuspid teeth both in the outer and inner row (Fig. 8a-e) (vs. a combination of tricuspid and unicuspid teeth in $\uparrow B$. sonyii sp. nov., and vs. mostly unicuspid teeth in $\uparrow B$. tallamae sp. nov.). The tricuspid teeth of $\dagger B$. senutae sp. nov. are characterized by a middle cusp that is only slightly longer than the lateral cusps (except in very small teeth, as shown in Fig. 8d), and by a rounded or slightly truncated shape of all three cusps (Fig. 8b, c, e). In contrast, tricuspid teeth of $\dagger B$. sonyii sp. nov. 


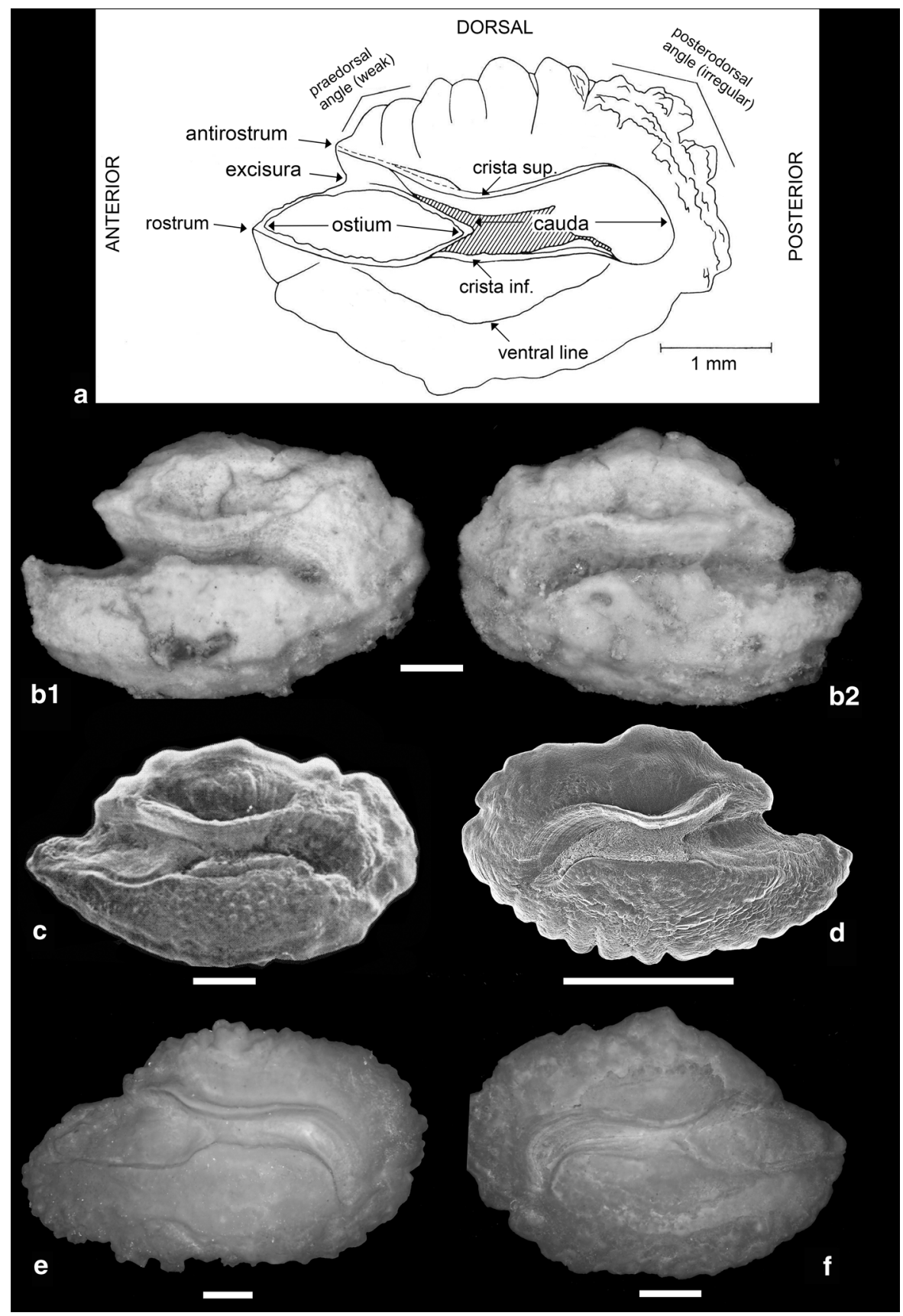

Fig. 9 Cichlid otoliths (sagittae). a Terminology of the mesial otolith surface based on a right sagitta of Haplochromis teegelaari Greenwood \& Barel, 1978 (SL $9.0 \mathrm{~cm})$, hatched area indicates the anterocaudal colliculum (source: Gaemers, 1984, modified), b $†$ Baringochromis senutae sp. nov., close up of right (b1) and left (b2) sagitta (OCO-5-23-R(2)), c Astatoreochromis alluaudi Pellegrin, 1903 (Haplochromini) (SL 10.1 cm, re-figured from Gamers, 1984: fig. 5a), d Tropheus duboisi Marlier, 1959 (Tropheini) (NHM 0382, TL/SL not known), e Oreochromis niloticus (Linnaeus, 1758) (Oreochromini) (mirrored for better comparison; SAPM-PI-03523, TL $25 \mathrm{~cm}$ ), f Sarotherodon galileus galileus (Linnaeus, 1758) (Oreochromini) (SAPM-PI-03528, TL $16 \mathrm{~cm}$ ). All scale bars $1 \mathrm{~mm}$ 
show an elevated middle cusp and all cusps are slightly pointed (Fig. 8h, k). †Baringochromis senutae sp. nov. is further distinct from $\dagger B$. sonyii sp. nov. by its greater head length (\% BL) (49.3-62.1 (54.6 \pm 3.3$)$ in $\dagger B$. senutae sp. nov. vs. $35.1-40.5(38.4 \pm 2.6)$ in $\dagger$ $B$. sonyii sp. nov.; ANCOVA, $P<0.05$ ), and from $\dagger B$. tallamae sp. nov. it is additionally separated by a more slender body depth at anal fin origin (\% BL) (23.5-34.8 (27.5 \pm 3.6$)$ in $\dagger B$. senutae sp. nov. vs. 32.9-37.7 (35.3 \pm 2.4$)$ in $\dagger B$. tallamae sp. nov.; ANCOVA, $P<0.05)$, and a shorter dorsal fin base ( $\%$ BL) (60.3-70.1 (65.6 \pm 2.6$)$ vs. 72.5; ANCOVA, $P<$ $0.05)$.

\section{General description}

As for genus. Ranges and means of measurements (in \% BL) and meristic characters of $\dagger B$. senutae sp. nov. are presented in Table 1 .

\section{$\dagger$ Baringochromis sonyii Altner \& Reichenbacher, sp. nov.}

(Figure 3c, d, 4a, 7d, 8f-k)

$$
\begin{aligned}
& \text { Holotype } \\
& \text { OCO-5-14/29(1). }
\end{aligned}
$$

\section{Paratypes}

Four skeletons.

Specimens with prefix OCO-5-: 16(4), 30, 37/42(1).

Specimens with prefix 2014-Wa-: 7(2).

\section{Further material}

Remains of five skeletons with preserved head and oral jaw dentition.

Specimens with prefix OCO-5-: 4, 8/23(6), 20a$\mathrm{R}(2)$, 43-R(3).

Specimens with prefix 2014-Wa-: 18a/b(2).

\section{Etymology}

Species named in honour of Stefan Sónyi, Munich, Germany, for his commitment and valuable help during fieldwork in Central Kenya and in acknowledgement of his excellent preparation of the fossil fish specimens.

\section{Type locality and age}

Outcrop Waril ( $\left.0^{\circ} 40^{\prime} 56.21^{\prime \prime} \mathrm{N} 35^{\circ} 43^{\prime} 7.43^{\prime \prime} \mathrm{E}\right)$ in Central Kenya (Fig. 1); upper Miocene (9-10 MYA).

\section{Differential diagnosis}

$\dagger$ Baringochromis sonyii sp. nov. differs from the two other species of $\dagger$ Baringochromis by its oral dentition, which consists of a combination of unicuspid and tricuspid teeth of different sizes (Fig. 8f-k). The outer row shows a mixture of large and small unicuspid and relatively large tricuspid teeth (Fig. 8g$\mathrm{i}, \mathrm{k}$ ), smaller tricuspid teeth occur in the inner row (Fig. 8f, j). Unicuspid teeth vary from conical to blunt to cone-shaped (Fig. 8g-i), tricuspid teeth have a middle cusp that is distinctively longer than the lateral cusps (Fig. 8f, h, j, k). †Baringochromis sonyii sp. nov. is further distinct from both $\dagger B$. senutae sp. nov. and $\dagger B$. tallamae sp. nov. by a shorter head (\% BL) (35.1-40.5 (38.4 \pm 2.6$)$ in $\dagger B$. sonyii vs. $49.3-62.1$ $(54.6 \pm 3.3)$ in $\dagger B$. senutae vs. $50.1-53.1(51.6 \pm 1.5)$ in $\dagger B$. tallamae; ANCOVA, $P<0.05)$. It additionally differs from $\dagger B$. tallamae sp. nov. by a shorter dorsal fin base (55.8-62.7 (60.8 \pm 3.3$)$ vs. 72.5; ANCOVA, $P<0.05)$.

\section{Description}

As for $\dagger B$. senutae sp. nov., with the exception of the characters mentioned in the differential diagnosis. For ranges and means of measurements (in \% BL) and meristic characters see Table 1.

\section{$\dagger$ Baringochromis tallamae Altner \& Reichen- bacher, sp. nov. \\ (Figure 3e, 7c, 81-r)}

\section{Holotype} 2014-WA-24a/b(1).

Paratype 2014-Wa-10.

\section{Further material}

Remains of two skeletons with preserved head and oral jaw dentition: OCO-5-20(4), 2014-WA-3(1).

\section{Etymology}

Species named after Mrs. Stella Tallam (Baringo County, Kenya), who significantly contributed to our fieldwork and successful excavations of fish fossils.

Type locality and age

Outcrop Waril ( $\left.0^{\circ} 40^{\prime} 56.21^{\prime \prime} \mathrm{N} 35^{\circ} 43^{\prime \prime} 7.43^{\prime \prime} \mathrm{E}\right)$ in Central Kenya (Fig. 1); upper Miocene (9-10 MYA). 


\section{Differential diagnosis}

$\dagger$ Baringochromis tallamae sp. nov. differs from both $\dagger B$. senutae sp. nov. and $\dagger B$. sonyii sp. nov. by the presence of mostly unicuspid oral jaw teeth (vs. solely tricuspid teeth in $\uparrow B$. senutae sp. nov. and vs. equal cooccurrence of tricuspid and unicuspid teeth in $\dagger B$. sonyii sp. nov.). Larger unicuspid teeth of $\uparrow B$. tallamae sp. nov. can be conical (Fig. 8p, q) or cone-shaped (Fig. 81, m), smaller unicuspid teeth can be shouldered-unicuspid or relatively thick and pointed (Fig. 8n, o). Tricuspid teeth occur rarely and have rounded cusps (Fig. 8r), their middle cusp is slightly higher than the lateral cusps, and the lateral cusps are slightly directed laterally (rather than straight, as seen in the other two species). $\uparrow$ Baringochromis tallamae sp. nov. is further distinct from both $\dagger B$. senutae sp. nov. and $\dagger B$. sonyii sp. nov. by its head length (\% BL) (50.1-53.1 (51.6 \pm 1.5$)$ in $\dagger B$. tallamae sp. nov., vs. 49.3-62.1 (54.6 \pm 3.3$)$ in $\dagger B$. senutae sp. nov., vs. 35.1-40.5 (38.4 \pm 2.6$)$ in $\dagger B$. sonyii sp. nov.; ANCOVA, $P<0.05)$ and a greater dorsal fin base (\% BL) (72.5 vs. 60.3-70.1 $(65.6 \pm 2.6)$ in $\dagger$ B. senutae sp. nov., vs. 55.8-62.7 (60.8 \pm 3.3$)$ in $\dagger B$. sonyii $\mathrm{sp.}$ nov.; ANCOVA, $P<0.05$ ). It is further distinct from $\dagger B$. senutae sp. nov. by a deeper body at anal fin origin (\% BL) (32.9-37.7 (35.3 \pm 2.4$)$ in $\dagger B$. tallamae sp. nov. vs. 23.5-34.8 (27.5 \pm 3.6$)$ in $\dagger$ B. senutae sp. nov.; ANCOVA, $P<0.05)$.

\section{Description}

As for $\dagger$ B. senutae sp. nov., with the exception of the characters mentioned in the differential diagnosis. For ranges and means of measurements (in \% BL) and meristic characters see Table 1 .

\section{Discussion}

Systematic classification of $\uparrow$ Baringochromis

$\dagger$ Baringochromis can be attributed to the Cichlidae based on its combination of osteological and finrelated characters (see "Results") and the presence of otoliths exhibiting an anterocaudal pseudocolliculum (sensu Gaemers, 1984). Its possession of a simple suture between the vomer and the parasphenoid, a single supraneural and four lateral-line tubules on the lacrimal permit it to be assigned to the subfamily Pseudocrenilabrinae, as has been confirmed by the phylogenetic analysis (Fig. 2). The dentition of the oral jaw allows to further refine the placement of $\dagger$ Baringochromis within the subfamily. In all of its species the teeth in the inner row are tricuspid, and this character is the only known synapomorphy of the members of the haplotilapiines (Schliewen \& Stiassny, 2003). †Baringochromis can therefore be interpreted as a member of the haplotilapiines.

For interpretation of $\dagger$ Baringochromis at the level of tribe, we adopted the 'best-fit approach' introduced in Penk et al. (2019). Accordingly, we compared the combination of characters displayed by $\dagger$ Baringochromis with a large dataset of extant species (see "Materials and methods") that includes representatives of all tribes and lineages of the haplotilapiines, and related published data (e.g. Trewavas, 1983; Greenwood, 1987; Stiassny, 1991; Takahashi, 2003a, b). The outcome reveals that the combination of a single supraneural + lacrimal with four lateralline tubules + five infraorbitals (io), as seen in $\dagger$ Baringochromis, occurs in only three of the 22 haplotilapiine tribes, namely the Cyprichromini, Haplochromini, and Oreochromini. Also a short io2 with a sensory canal as seen in $\dagger$ Baringochromis is found only in these three tribes (Takahashi, 2003b).

Before it can be considered to which of the three candidate tribes the new fossil taxon can be attributed, one conspicuous character of the preopercle of $\dagger$ Baringochromis, i.e. the presence of only three lateral-line tubules on its lower (horizontal) arm (Fig. 4d2), deserves further comment. In African cichlids, the preopercle usually has four lateral-line tubules on the lower arm, and the bone bears seven lateral-line tubules in all (Stiassny, 1991; Takahashi, 2002: fig. 2A). In contrast, South American cichlids have three lateral-line tubules on the lower arm of the preopercle (like $†$ Baringochromis), and correspondingly a total of six altogether (Kullander, 1986: fig. 13H). However, deviations from the usual configuration of the African cichlids do occur, albeit rarely, among the members of three tribes. The condition seen in $†$ Baringochromis has been reported for a nonhaplotilapiine tribe, i.e. the chromidotilapiines (genus Congochromis, see Stiassny \& Schliewen, 2007), and also for one extinct and one extant member of a haplotilapiine tribe, the Oreochromini (†Rebekkachromis and Oreochromis (Alcolapia), see Kevrekidis et al., in press). Moreover, a different 
haplotilapiine tribe-the Trematocarini-deviates from all others in having five tubules on the lower preopercle arm (see Takahashi, 2002: fig. 2B). The occurrence of three lateral-line tubules on the lower arm of the preopercle in South American cichlids, as well as in two distantly related tribes of the African cichlids, indicates that this character is homoplastic. Therefore, we do not consider it further in our application of the best-fit approach to the classification of $\dagger$ Baringochromis.

Another potentially useful character for systematic classification is the presence or absence of a projection on the anterodorsal surface of the urohyal bone. According to Takahashi (2003a), the plesiomorphic state is characterized by the presence of such a projection, and the apomorphic state by its virtual or complete absence (as in †Baringochromis). The matrix presented in Takahashi (2003a) indicates that among the three candidate tribes to which $\dagger$ Baringochromis most likely belongs, only the Cyprichromini possesses this condition. However, Takahashi's matrix focused on the Lake Tanganyika cichlids and is thus not representative for the tribes Oreochromini and Haplochromini (most of which are found elsewhere). Additional information on the urohyal condition is provided by Stiassny (1981b) and Greenwood (1989), who described a urohyal lacking the anterodorsal projection for the extant Haplochromini Rhamphochromis and Pseudocrenilabrus, respectively. But the same condition of the urohyal has also been reported for two fossil oreochromine genera ( $\dagger$ Oreochromimos and †Rebekkachromis, see Penk et al., 2019 and Kevrekidis et al., in press). Thus, it appears that Stiassny (1981b) was correct in assuming that the lack of the anterodorsal urohyal projection is a condition that has evolved independently in several lineages. This compromises the character's ability to support the attribution of $\uparrow$ Baringochromis to a particular tribe.

Nevertheless, its meristic traits preclude assignment of $\uparrow$ Baringochromis to the Cyprichromini. Unlike Haplochromini and Oreochromini, Cyprichromini has many more vertebrae (35-40 vs. 27-29) and dorsal fin rays (10-18 vs. 7-10) than $\uparrow$ Baringochromis (Table 2). In addition, previous studies by Poll (1981, 1986), Büscher (1994) and Takahashi (2004) have shown that the genus Cyprichromis (but not Paracyprichromis) is characterized by an abdominal cavity that is extended posteriorly, i.e. it reaches beyond the anal-fin origin (Poll, 1981: p. 173, fig. 3A). We interpret the black organic remains that are recognizable below the tips of the ribs up to the origin of the anal fin (Fig. 3c, e) as possible remains of the abdominal cavity or stomach contents, which would imply that the abdominal cavity did not extend beyond the anal-fin origin.

Taking all osteological and meristic data together, two candidate tribes remain: the Haplochromini and the Oreochromini. Therefore we turned to the otoliths of $\dagger$ Baringochromis as a potential source of additional insights. Saccular otoliths (termed otoliths in the following) are established tools in taxonomic and systematic studies of teleosts (Nolf, 1985; 2013; see Fig. 9a for otolith terminology). Although little information is available for cichlid otoliths, previous studies have demonstrated their usefulness in cichlid systematics (Gaemers, 1984, 1986; Gaemers \& Crapon de Crapona, 1986; unpublished data of the authors). Here we have considered images depicting otoliths of the Oreochromini and Haplochromini from previous works (Tichy \& Seegers, 1999; Gaemers, 1984, 1986), together with newly assembled material from museum collections (Fig. 9c-f). Comparisons with the otoliths of $\dagger$ Baringochromis (Fig. 9b) show that the latter differ from those of the Oreochromini (Fig. 9e, f) in that the area of the ostium is smaller, the excisura is deeper, the antirostrum more pronounced, and the end of the cauda less curved downwards. In all these respects, the otoliths of $\dagger$ Baringochromis are similar to the otoliths of Astatoreochromis alluaudi (Haplochromini, Fig. 9c) and Tropheus duboisi (Tropheini, Fig. 9d). Three of the aforementioned characters (small ostium, deep excisura, pronounced antirostrum) are rarely seen in cichlid otoliths (Gaemers, 1984, 1986, unpublished data of the authors), and thus seem likely to represent synapomorphies shared by the members of the Haplochromini and Tropheini. Consequently, we tentatively attribute $\dagger$ Baringochromis to the Haplochromini.

\section{Possible modern analogues of palaeolake Waril}

The co-occurrence of three superficially similar species of $\dagger$ Baringochromis, which are differentiated solely by their oral dentition and a few morphometric traits (mainly related to the head and dorsal fin 
base), indicate the presence of a small fossil species flock in the ancient lake Waril. Reviewing the literature dealing with lakes inhabited by a small cichlid species flock, we found possible modern analogues of palaeolake Waril in Africa (see below) and, with Lake Apoyo in Nicaragua, also in the New World. Lake Apoyo-with a surface area of 21 $\mathrm{km}^{2}$-was created by explosive volcanism about 23,000 years ago, and its waters are warm $\left(27-29.5^{\circ} \mathrm{C}\right)$ and alkaline (pH 8.1) (Stauffer et al., 2008). Similar conditions can be assumed for palaeolake Waril based on geological, palaeontological and mineralogical evidence: (i) Explosive volcanism is shown by the tuff beneath the lake sediments (Fig. 1d, f); (ii) the restricted thickness of the lacustrine sediments $(\sim 10 \mathrm{~m})$ indicates that the palaeolake existed for only a short period of time ( 10,000-20,000 years); (iii) the fossil floral assemblage recovered from the lake sediments point to warm climate (Jacobs, 2002; Bonnefille, 2010); and (iv) the dominance of the minerals heulandite $(30 \%)$ and analcime $(42 \%)$ point to volcanic activity and the existence of an alkaline water body, respectively (Rasmussen et al., 2017). Lake Apoyo is inhabited by a species flock comprising six species of the cichline genus Amphilophus that evolved by sympatric speciation (Geiger et al., 2010). Likewise, the species flock of $\dagger$ Baringochromis may have evolved (see below).

In Africa, three lakes in Cameroon, namely the volcanic crater lakes Lake Barombi Mbo, Lake Bermin and Lake Ejagham-albeit small, with surface areas of $0.49-4.15 \mathrm{~km}^{2}$-represent possible modern analogues (Schliewen et al., 1994, 2001; Schliewen \& Klee, 2004). Lake Barombi Mbo (area $4.15 \mathrm{~km}^{2}$ ) is home to a species flock comprising 11 species, while Lake Bermin (area $0.6 \mathrm{~km}^{2}$ ) has an endemic species flock encompassing nine species (Schliewen et al.,
1994). Each of these species flocks has evolved by sympatric speciation in the course of trophic and reproductive differentiation (Schliewen et al., 1994). Hybridization may also have contributed to the diversity of the flock found in Barombi Mbo (Schliewen \& Klee, 2004). The third lake, Lake Ejagham has a surface area of $0.49 \mathrm{~km}^{2}$, has been in existence for a short time (c. 10,000 years), and is inhabited by a flock of five Tilapia forms derived from a riverine founder species (Schliewen et al., 2001). In addition, Schliewen et al. (2001) precisely documented the differentiated composition of the bottom of Lake Ejagham. Leaves, twigs, insects and their aquatic larvae cover the lake floor near the shoreline. At intermediate depths, the substrate is sandy, while the central (deepest) part of the lake is covered with mud that is rich in organic material. This last sector is a perfect actualistic model for the very well preserved fish fossils in the palaeolake Waril, as such a sediment is deficient in oxygen and facilitates fossil conservation. The insights provided by Lake Ejagham also offer a possible explanation for the fact that we encountered a single fossil insect and only a few fossil leaves, whereas numerous such finds had previously been reported by Pickford (1978): these remains had mostly accumulated nearer to the shoreline of the ancient lake.

\section{The $†$ Baringochromis species flock}

Palaeolake Waril was probably connected to a small river or stream, which is indicated by fossil remains of a crocodile, turtles and a few (transported) mammal bones, which were found a few metres above the lake sediments (Rasmussen et al., 2017). A riverine cichlid founder species may thus have entered the palaeolake, as suggested for Lake

Table 2 Range of meristic counts of $\dagger$ Baringochromis and the three candidate tribes to which it principally could belong

\begin{tabular}{lllcll}
\hline & Vertebrae & Dorsal fin spines & Dorsal fin rays & Anal fin spines & Anal fin rays \\
\hline$\dagger$ Baringochromis & $27-29$ & XI-XIII & $7-10$ & III & $7-10$ \\
Cyprichromini & $35-40$ & XI-XVIII & $10-18$ & III & $7-14$ \\
Haplochromini & $26-37$ & XII-XXII & $6-18$ & II-VII & $5-13$ \\
Oreochromini & $26-34$ & IX-XIX & $8-15$ & II-VI & $6-14$ \\
\hline
\end{tabular}

Counts from comparative dataset (this study) and literature (see Penk et al., 2019 and Altner et al., 2020 for details of references) 
Ejagham by Schliewen et al. (2001). It may have colonized the new habitat by rapid adaptation to different environments-rocky shore, sandy bottom, and pelagic zone (see Schliewen et al., 2001; Sturmbauer et al., 2011). In the next phase of radiation, the newly evolved species may have begun to subdivide their initial niches by trophic differentiation (Sturmbauer et al., 2011). The three species of $\dagger$ Baringochromis may well have emerged at this latter stage. Possible sources of food could have been plant debris and insects, as their fossilized remains are known from Waril (Pickford, 1978; Pickford et al., 2009). Accordingly, the three species of $\dagger$ Baringochromis may have specialized by feeding on either plant debris or insects. Whether or not other feeding strategies, such as paedophagy or scale-eating (see Vranken et al., 2019), were also exploited in palaeolake Waril must remain speculative. The fourth species recorded from the site, $\dagger$ Warilochromis unicuspidatus, was interpreted as a predatory species (Altner et al., 2020); it may have fed on young fish. The fifth cichlid species from Waril is †Tugenchromis pickfordi, of which the dentition is not known (Altner et al., 2017). But its rarity suggests that it may have lived near the rocky shore of the lake, which would be expected to be less conducive to the preservation of complete fossil fishes.

In the fossil record, evidence for species flocks is comparatively rare and only two other examples are known for fossil cichlids. One is from the Eocene volcanic crater lake of Mahenge in Tanzania (East Africa). Lake Mahenge was small $\left(<0.5 \mathrm{~km}^{2}\right)$ and inhabited by five species of $\uparrow$ Mahengechromis, which were mainly differentiated by their head shapes (Murray 2000). The second example is a possible species flock in statu nascendi of the oreochromine genus $\uparrow$ Rebekkachromis from alkaline lake deposits of the middle and upper Miocene of the Tugen Hills (Kevrekidis et al., in press). The late Miocene species flock of $\dagger$ Baringochromis provides the third case of an ancient cichlid species flock, and possibly the first fossil record of a haplochromine species flock.

Acknowledgements Open Access funding provided by Projekt DEAL. The Research Authorisation (NCST/RCD/12B/ 012/54) was provided by the Kenyan National Council for Science and Technology (Nairobi). We are very grateful to W. Moturi, J.M. Mironga, and K.N.N. Ondimu (all of the Faculty of Environment \& Resources Development, Egerton University,
Kenya) as well as to B. Senut (Sorbonne-Universités, Paris, France) for their essential scientific and logistical support. We thank M. Pickford (Musée National d'Histoire Naturelle, Paris, France) and the members of the Orrorin Community Organisation (Baringo County, Kenya), who helped in all aspects of the fieldwork and provided support for our project. We are grateful to S. Sónyi (SNSB-Bavarian State Collection of Palaeontology and Geology (BSPG), Munich, Germany) for the preparation of the fish fossils in the field, and to $\mathrm{M}$. Schellenberger (SNSB-BSPG) and C. Kevrekidis (LMU Munich, Germany) for preparing the photographs shown in Fig. 3. We thank H. Obermeier, B. Möllenkamp and N. Pöllath (SAPM, Munich, Germany) and U. Göhlich (Natural History Museum Vienna, Austria) for providing access to the respective otolith collections of their institutions. We thank U. Schliewen and F. Schedel (both SNSB-Bavarian State Collection of Zoology, Munich, Germany), C. Kevrekidis and S. Penk (both LMU Munich, Germany) for constructive discussions. We are indebted to M. Dohrmann (LMU Munich, Germany) for valuable advice concerning the phylogenetic methods and interpretations. Special thanks go to G. Arratia (University of Kansas, Lawrence, USA) and again to M. Pickford (Musée National d'Histoire Naturelle, Paris, France) for continuous scientific advice and insightful discussions. We thank G. Wörheide and M. Reich, Director and Vice-Director of SNSBBSPG for their kind support, and P. Hardy (Düsseldorf, Germany) for critical reading of the manuscript. Finally, we acknowledge funding for this work from the German Science Foundation (RE 1113/18-2).

Open Access This article is licensed under a Creative Commons Attribution 4.0 International License, which permits use, sharing, adaptation, distribution and reproduction in any medium or format, as long as you give appropriate credit to the original author(s) and the source, provide a link to the Creative Commons licence, and indicate if changes were made. The images or other third party material in this article are included in the article's Creative Commons licence, unless indicated otherwise in a credit line to the material. If material is not included in the article's Creative Commons licence and your intended use is not permitted by statutory regulation or exceeds the permitted use, you will need to obtain permission directly from the copyright holder. To view a copy of this licence, visit http://creativecommons.org/licenses/by/4.0/.

\section{References}

Albertson, R. C., J. T. Streelman \& T. D. Kocher, 2003. Directional selection has shaped the oral jaws of Lake Malawi cichlid fishes. Proceedings of the National Academy of Sciences USA 100(9): 5252-5257.

Altner, M., B. Ruthensteiner \& B. Reichenbacher, 2020. New haplochromine cichlid from the upper Miocene (9-10 MYA) of Central Kenya. BMC Evolutionary Biology. https://doi.org/10.1186/s12862-020-01602-x.

Altner, M., U. K. Schliewen, S. B. R. Penk \& B. Reichenbacher, 2017. $\dagger$ Tugenchromis pickfordi, gen. et sp. nov., from the upper Miocene-a stem-group cichlid of the 'East African 
Radiation' Journal of Vertebrate Paleontology. https://doi. org/10.1080/02724634.2017.1297819.

Barel, C. D. N., F. Witte \& M. J. P. Van Oijen, 1976. The shape of the skeletal elements in the head of a generalized Haplochromis species: H. elegans Trewavas 1933 (Pisces, Cichlidae). Netherlands Journal of Zoology 26(2): 163-265.

Betancur, R., E. O. Wiley, G. Arratia, A. Acero, N. Bailly, M. Miya, G. Lecointre \& G. Ortí, 2017. Phylogenetic classification of bony fishes. BMC Evolutionary Biology 17(1): 162.

Bishop, W. W. \& G. R. Chapman, 1970. Early Pliocene sediments and fossils from the Northern Kenya Rift Valley. Nature 226: 914-918.

Bishop, W. W. \& M. H. L. Pickford, 1975. Geology, fauna and palaeoenvironments of the Ngorora Formation, Kenya Rift Valley. Nature 254: 185-192.

Bonnefille, R., 2010. Cenozoic vegetation, climate changes and hominid evolution in tropical Africa. Global and Planetary Change 72(4): 390-411.

Brawand, D., C. E. Wagner, Y. I. Li, M. Malinsky, I. Keller, S. Fan, O. Simakov, A. Y. Ng, Z. W. Lim, E. Bezault, J. Turner-Maier, J. Johnson, R. Alcazar, H. J. Noh, P. Russell, B. Aken, J. Alfoldi, C. Amemiya, N. Azzouzi, J. F. Baroiller, F. Barloy-Hubler, A. Berlin, R. Bloomquist, K. L. Carleton, M. A. Conte, H. D'Cotta, O. Eshel, L. Gaffney, F. Galibert, H. F. Gante, S. Gnerre, L. Greuter, R. Guyon, N. S. Haddad, W. Haerty, R. M. Harris, H. A. Hofmann, T. Hourlier, G. Hulata, D. B. Jaffe, M. Lara, A. P. Lee, I. MacCallum, S. Mwaiko, M. Nikaido, H. Nishihara, C. Ozouf-Costaz, D. J. Penman, D. Przybylski, M. Rakotomanga, S. C. Renn, F. J. Ribeiro, M. Ron, W. Salzburger, L. Sanchez-Pulido, M. E. Santos, S. Searle, T. Sharpe, R. Swofford, F. J. Tan, L. Williams, S. Young, S. Yin, N. Okada, T. D. Kocher, E. A. Miska, E. S. Lander, B. Venkatesh, R. D. Fernald, A. Meyer, C. P. Ponting, J. T. Streelman, K. Lindblad-Toh, O. Seehausen \& F. Di Palma, 2014. The genomic substrate for adaptive radiation in African cichlid fish. Nature 513(7518): 375-381.

Büscher, H. H., 1994. Cyprichromis pavo n. sp.: Ein neuer Cichlide aus dem Tanganjikasee (Cichlidae, Cyprichromini). Deutsche Aquarien und Terrarien Zeitschrift 46(4): 257-263.

Carnevale, G., C. Sorbini \& W. Landini, 2003. Oreochromis lorenzoi, a new species of tilapiine cichlid from the Late Miocene of central Italy. Journal of Vertebrate Paleontology 23(3): 508-516.

Carpenter, K. E. \& V. H. Niem, 2001. FAO Species Identification Guide for fishery purposes. The Living Marine Resources of the Western Central Pacific. Volume 5. Bony Fishes Part 3 (Menidae to Pomacentridae). FAO, Rome.

Casciotta, J. \& G. Arratia, 1993. Tertiary cichlid fishes from Argentina and reassessment of the phylogeny of New World cichlids (Perciformes: Labroidei). Kaupia - Darmstädter Beiträge zur Naturgeschichte 2: 195-240.

Cichocki, F. P., 1976. Cladistic History of Cichlid Fishes and Reproductive Strategies of the American Genera Acarichthys, Biotodoma and Geophagus. (Volumes I and II). University of Michigan, Michigan.
Fryer, G. \& T. D. Iles, 1972. The Cichlid Fishes of the Great Lakes of Africa: Their Biology and Evolution. Oliver \& Boyd, Edinburgh.

Fujita, K., 1990. The Caudal Skeleton of Teleostean Fishes. Tokai University Press, Tokyo.

Gaemers, P. A. M., 1984. Taxonomic position of the Cichlidae (Pisces, Perciformes) as demonstrated by the morphology of their otoliths. Netherlands Journal of Zoology 34(4): 566-595.

Gaemers, P. A. M., 1986. Recent progress in cichlid taxonomy based on otoliths, and its significance for the phylogeny of tilapiines and haplochromines (Perciformes, Pisces). Annalen- Zoologische Wetenschappen 251: 143-150.

Gaemers, P. A. M. \& M.-D. Crapon de Crapona, 1986. Sexual dimorphism in otoliths of haplochromines (Pisces, Cichlidae). Annalen - Zoologische Wetenschappen 251: 151-155.

Geiger, M. F., J. K. McCrary \& J. R. Stauffer Jr., 2010. Description of two new species of the Midas cichlid complex (Teleostei: Cichlidae) from Lake Apoyo, Nicaragua. Proceedings of the Biological Society of Washington 123(2): 159-173.

Goloboff, P. A., J. S. Farris \& K. C. Nixon, 2008. TNT, a free program for phylogenetic analysis. Cladistics 24(5): 774-786.

Goloboff, P. A., A. Torres \& J. S. Arias, 2018. Weighted parsimony outperforms other methods of phylogenetic inference under models appropriate for morphology. Cladistics 34: 407-437.

Greenwood, P. H., 1987. The genera of pelmatochromine fishes (Teleostei, Cichlidae). A phylogenetic review. Bulletin of the British Museum (Natural History) 53(3): 139-203.

Greenwood, P. H., 1989. The taxonomic status and phylogenetic relationships of Pseudocrenilabrus Fowler (Teleostei, Cichlidae). Ichthyological Bulletin of the J L B Smith Institute of Ichthyology 54: 1-16.

Hammer, Ø., D. A. T. Harper \& P. D. Ryan, 2001. PAST: Paleontological statistics software package for education and data analysis. Palaeontologia Electronica 4(1): 1-9.

Hillis, D. M. \& J. J. Bull, 1993. An empirical test of bootstrapping as a method for assessing confidence in phylogenetic analysis. Systematic Biology 42(2): 182-192.

Jacobs, B. F., 2002. Estimation of low-latitude paleoclimates using fossil angiosperm leaves: examples from the Miocene Tugen Hills, Kenya. Paleobiology 28(3): 399-421.

Kevrekidis, C., B. Ruthensteiner, A. F. Cerwenka, S. B. R. Penk $\&$ B. Reichenbacher, in press. New cichlid fossils from the middle-late Miocene alkaline lakes of Africa. Journal of Vertebrate Paleontology.

Kevrekidis, C., M. Valtl, S. B. R. Penk, M. Altner \& B. Reichenbacher, 2019. Rebekkachromis nov. gen. from the middle-upper Miocene (11 MYA) of Central Kenya: the oldest record of a haplotilapiine cichlid fish. Hydrobiologia 832(1): 39-64.

Koblmüller, S., B. Egger, C. Sturmbauer \& K. M. Sefc, 2010. Rapid radiation, ancient incomplete lineage sorting and ancient hybridization in the endemic Lake Tanganyika cichlid tribe Tropheini. Molecular Phylogenetics and Evolution 55(1): 318-334.

Koblmüller, S., U. K. Schliewen, N. Duftner, K. M. Sefc, C. Katongo \& C. Sturmbauer, 2008. Age and spread of the 
haplochromine cichlid fishes in Africa. Molecular Phylogenetics and Evolution 49(1): 153-169.

Kullander, S. O., 1986. Cichlid Fishes of the Amazon River Drainage of Peru. Department of Vertebrate Zoology, Swedish Museum of Natural History, Stockholm.

Kullander, S. O., 1998. A phylogeny and classification of the South American Cichlidae (Teleostei: Perciformes). In Malabarba, L. R., R. E. Reis, R. P. Vari, Z. M. Lucena \& C. A. S. Lucena (eds), Phylogeny and Classification of Neotropical Fishes Part 5 - Perciformes. Edipucrs, Porto Alegre: 461-498.

Maddison, W. P. \& D. R. Maddison, 2019. Mesquite: a modular system for evolutionary analysis. Version $3.6 \mathrm{http}: / /$ mesquiteproject.org. 3.6 edn.

Malabarba, M. C., L. R. Malabarba \& H. López-Fernández, 2014. On the Eocene cichlids from the Lumbrera Formation: additions and implications for the neotropical ichthyofauna. Journal of Vertebrate Paleontology 34(1): 49-58.

Murray, A. M., 2000. Eocene cichlid fishes from Tanzania, East Africa. Journal of Vertebrate Paleontology 20(4): 651-664.

Murray, A. M., T. Argyriou, S. Cote \& L. MacLatchy, 2017. The Fishes of Bukwa, Uganda, a Lower Miocene (Burdigalian) Locality of East Africa. Journal of Vertebrate Paleontology. https://doi.org/10.1080/02724634.2017.1324460.

Nolf, D., 1985. Handbook of Paleoichthyology, Volume 10, Otolithi piscium, vol 10. Verlag Dr. Friedrich Pfeil, München.

Nolf, D., 2013. The Diversity of Fish Otoliths, Past and Present. Royal Belgian Institute of Natural Sciences, Brussels.

Penk, S. B. R., M. Altner, A. F. Cerwenka, U. K. Schliewen \& B. Reichenbacher, 2019. New fossil cichlid from the middle Miocene of East Africa revealed as oldest known member of the Oreochromini. Scientific Reports 9(1): 10198.

Pickford, M., 1978. Geology, palaeoenvironments and vertebrate faunas of the mid-Miocene Ngorora Formation, Kenya. Geological Society, London, Special Publications 6: 237-262.

Pickford, M., B. Senut \& K. Cheboi, 2009. The geology and paleobiology of the Tugen Hills, Kenya. Geo-Pal Kenya 1: $1-134$.

Poll, M., 1920. Contribution a la faune ichthyologique de lac Tanganyika. Révision du genre Limnochromis Regan, 1920. Description de trois genres nouveaux et d'une espèce nouvelle: Cyprichromis brieni. Annales de la Societe Royale Zoologique de Belgique 111(1-4): 163-179.

Poll, M., 1986. Classification des Cichlidae du lac Tanganika: Tribus, genres et espèces. Académie Royale de Belgique Mémoires de la Classe des Sciences 45(2): 1-163.

Rambaut, A., 2018. FigTree. Tree Figure Drawing Tool version 1.4.4. http://tree.bio.ed.ac.uk/software/figtree/. 1.4.4 edn. University of Edinburgh, Edinburgh.

Rasmussen, C., B. Reichenbacher, O. Lenz, M. Altner, S. B. R. Penk, J. Prieto \& D. Brüsch, 2017. Middle-late Miocene palaeoenvironments, palynological data and a fossil fish Lagerstätte from the Central Kenya Rift (East Africa). Geological Magazine 154(1): 24-56.

Salzburger, W., 2018. Understanding explosive diversification through cichlid fish genomics. Nature Reviews Genetics 19: 705-717.
Salzburger, W., T. Mack, E. Verheyen \& A. Meyer, 2005. Out of Tanganyika: genesis, explosive speciation, key-innovations and phylogeography of the haplochromine cichlid fishes. BMC Evolutionary Biology 5: 17.

Salzburger, W., B. Van Bocxlaer \& A. S. Cohen, 2014. Ecology and evolution of the African Great Lakes and their faunas. Annual Review of Ecology Evolution and Systematics 45(1): 519-545.

Schliewen, U., K. Rassmann, M. Markmann, J. Markert, T. Kocher \& D. Tautz, 2001. Genetic and ecological divergence of a monophyletic cichlid species pair under fully sympatric conditions in Lake Ejagham, Cameroon. Molecular Ecology 10: 1471-1488.

Schliewen, U. K. \& B. Klee, 2004. Reticulate sympatric speciation in Cameroonian crater lake cichlids. Frontiers in Zoology. https://doi.org/10.1186/1742-9994-1-5.

Schliewen, U. K. \& M. L. Stiassny, 2003. Etia nguti, a new genus and species of cichlid fish from the River Mamfue, Upper Cross River basin in Cameroon, West-Central Africa. Ichthyological Exploration of Freshwaters 14(1): 61-71.

Schliewen, U. K., D. Tautz \& S. Pääbo, 1994. Sympatric speciation suggested by monophyly of crater lake cichlids. Nature 368: 629-632.

Schwarzer, J., E. R. Swartz, E. Vreven, J. Snoeks, F. P. D. Cotterill, B. Misof \& U. K. Schliewen, 2012. Repeated trans-watershed hybridization among haplochromine cichlids (Cichlidae) was triggered by Neogene landscape evolution. Proceedings of the Royal Society B-Biological Sciences 279: 4389-4398.

Sebilia, A. S. C. \& J. V. Andreata, 1991. Osteology of the caudal fin of some species of Cichlidae (Pisces, Perciformes, Labroidei). Revista Brasileira de Zoologia 7(3): 307-318.

Seehausen, O., 2006. African cichlid fish: a model system in adaptive radiation research. Proceedings of the Royal Society, B - Biological Sciences 273(1597): 1987-1998.

Seehausen, O., 2015. Process and pattern in cichlid radiations inferences for understanding unusually high rates of evolutionary diversification. The New Phytologist 207(2): 304-312.

Sparks, J. S. \& W. L. Smith, 2004. Phylogeny and biogeography of cichlid fishes (Teleostei: Perciformes: Cichlidae). Cladistics 20(6): 501-517.

Stauffer Jr., J. R., J. K. McCrary \& K. E. Black, 2008. Three new species of cichlid fishes (Teleostei : Cichlidae) from Lake Apoyo, Nicaragua. Proceedings of the Biological Society of Washington 121(1): 117-129.

Stiassny, M. L. J., 1981a. The phyletic status of the family Cichlidae (Pisces, Perciformes): a comparative anatomical investigation. Netherlands Journal of Zoology 31(2): 275-314.

Stiassny, M. L. J., 1981b. Phylogenetic versus convergent relationship between piscivorous cichlid fishes from Lakes Malawi and Tanganyika. Bulletin of the British Museum (Natural History) Zoology series 40(3): 67-101.

Stiassny, M. L. J., 1991. Phylogenetic intrarelationships of the family Cichlidae. In Keenleyside, M. H. A. (ed.), Cichlid Fishes. Chapman \& Hall, London: 1-35.

Stiassny, M. L. J. \& U. K. Schliewen, 2007. Congochromis, a new cichlid genus (Teleostei: Cichlidae) from Central Africa, with the description of a new species from the 
Upper Congo River, Democratic Republic of Congo. American Museum Novitates 3576: 1-14.

Sturmbauer, C., M. Husemann \& P. D. Danley, 2011. Explosive speciation and adaptive radiation of East African cichlid fishes. In Zachos, F. \& J. Habel (eds), Biodiversity Hotspots. Springer, Berlin, Heidelberg: 333-362.

Takahashi, T., 2002. Systematics of the tribe Trematocarini (Perciformes: Cichlidae) from Lake Tanganyika, Africa. Ichthyological Research 49: 253-259.

Takahashi, T., 2003a. Comparative osteology of the infraorbitals in cichlid fishes (Osteichthyes: Teleostei: Perciformes) from Lake Tanganyika. Species Diversity 8: 1-26.

Takahashi, T., 2003b. Systematics of Tanganyikan cichlid fishes (Teleostei: Perciformes). Ichthyological Research 50(4): 367-382.

Takahashi, T., 2004. Phylogenetic analysis of Cyprichromini (Perciformes: Cichlidae) endemic to Lake Tanganyika and validation of the genus Paracyprichromis. Ichthyological Research 51: 1-4.

Takahashi, T. \& K. Nakaya, 2002. Description and familial allocation of the African fluvial genus Teleogramma to the Cichlidae. Ichthyological Research 49(2): 171-180.
Tichy, H. \& L. Seegers, 1999. The Oreochromis alcalicus flock (Teleostei: Cichlidae) from lakes Natron and Magadi, Tanzania and Kenya: a model for the evolution of "new" species flocks in historical times? Ichthyological Exploration of Freshwaters 10(2): 147-174.

Trewavas, E., 1983. Tilapiine Fishes of the Genera Sarotherodon, Oreochromis and Danakilia. British Museum (Natural History), London.

Van Couvering, J. A. H., 1982. Fossil cichlid fish of Africa. Special Papers in Paleontology 29: 1-103.

Vandewalle, P., 1973. Ostéologie caudale des Cichlidae (Pisces, Teleostei). Bulletin biologique de la France et de la Belgique 107(4): 275-289.

Vranken, N., M. Van Steenberge \& J. Snoeks, 2019. Grasping ecological opportunities: not one but five paedophagous species of Haplochromis (Teleostei: Cichlidae) in the Lake Edward system. Hydrobiologia 832: 105-134.

Publisher's Note Springer Nature remains neutral with regard to jurisdictional claims in published maps and institutional affiliations. 